\title{
Comparison of global datasets of sodium densities in the mesosphere and lower thermosphere from GOMOS, SCIAMACHY and OSIRIS measurements and WACCM model simulations from 2008 to 2012
}

\author{
Martin P. Langowski ${ }^{1}$, Christian von Savigny ${ }^{1}$, John P. Burrows ${ }^{2}$, Didier Fussen ${ }^{3}$, Erin C. M. Dawkins ${ }^{4,5}$, \\ Wuhu Feng ${ }^{6,7}$, John M. C. Plane ${ }^{6}$, and Daniel R. Marsh ${ }^{8}$ \\ ${ }^{1}$ Institute of Physics, Ernst Moritz Arndt University of Greifswald, Greifswald, Germany \\ ${ }^{2}$ Institute of Environmental Physics, University of Bremen, Bremen, Germany \\ ${ }^{3}$ Belgian Institute for Space Aeronomy, Brussels, Belgium \\ ${ }^{4}$ NASA Goddard Space Flight Center, Greenbelt, MD, USA \\ ${ }^{5}$ Department of Physics, Catholic University of America, Washington, DC, USA \\ ${ }^{6}$ School of Chemistry, University of Leeds, Leeds, UK \\ ${ }^{7}$ National Center for Atmospheric Science, School of Earth and Environment, University of Leeds, Leeds, UK \\ ${ }^{8}$ National Center for Atmospheric Research, Boulder, CO, USA \\ Correspondence to: Martin P. Langowski (langowskim_uni_greifswald@gmx.de)
}

Received: 22 December 2016 - Discussion started: 20 January 2017

Revised: 13 April 2017 - Accepted: 19 April 2017 - Published: 21 August 2017

\begin{abstract}
During the last decade, several limb sounding satellites have measured the global sodium $(\mathrm{Na})$ number densities in the mesosphere and lower thermosphere (MLT). Datasets are now available from Global Ozone Monitoring by Occultation of Stars (GOMOS), the SCanning Imaging Absorption spectroMeter for Atmospheric CHartography (SCIAMACHY) (both on Envisat) and the Optical Spectrograph and InfraRed Imager System (OSIRIS) (on Odin). Furthermore, global model simulations of the $\mathrm{Na}$ layer in the MLT simulated by the Whole Atmosphere Community Climate Model, including the Na species (WACCM-Na), are available. In this paper, we compare these global datasets.

The observed and simulated monthly averages of $\mathrm{Na}$ vertical column densities agree reasonably well with each other. They show a clear seasonal cycle with a summer minimum most pronounced at the poles. They also show signs of a semi-annual oscillation in the equatorial region. The vertical column densities vary from $0.5 \times 10^{9}$ to $7 \times 10^{9} \mathrm{~cm}^{-2}$ near the poles and from $3 \times 10^{9}$ to $4 \times 10^{9} \mathrm{~cm}^{-2}$ at the Equator. The phase of the seasonal cycle and semi-annual oscillation shows small differences between the $\mathrm{Na}$ amounts retrieved from different instruments. The full width at half maximum of the profiles is 10 to $16 \mathrm{~km}$ for most latitudes, but significantly smaller in the polar summer. The centroid altitudes
\end{abstract}

of the measured sodium profiles range from 89 to $95 \mathrm{~km}$, whereas the model shows on average 2 to $4 \mathrm{~km}$ lower centroid altitudes. This may be explained by the mesopause being $3 \mathrm{~km}$ lower in the WACCM simulations than in measurements. Despite this global $2-4 \mathrm{~km}$ shift, the model captures well the latitudinal and temporal variations. The variation of the WACCM dataset during the year at different latitudes is similar to the one of the measurements. Furthermore, the differences between the measured profiles with different instruments and therefore different local times (LTs) are also present in the model-simulated profiles. This capturing of latitudinal and temporal variations is also found for the vertical column densities and profile widths.

\section{Introduction}

The metal layers in the mesosphere and lower thermosphere (MLT) are formed by ablation from meteoroids entering the Earth's atmosphere (see, e.g., Plane (2003) and Plane et al. (2015) for reviews). The main source of these meteoroids is cometary dust from the Jupiter-family comets (see, e.g., Nesvorný et al., 2010), which produce a dominating contin- 

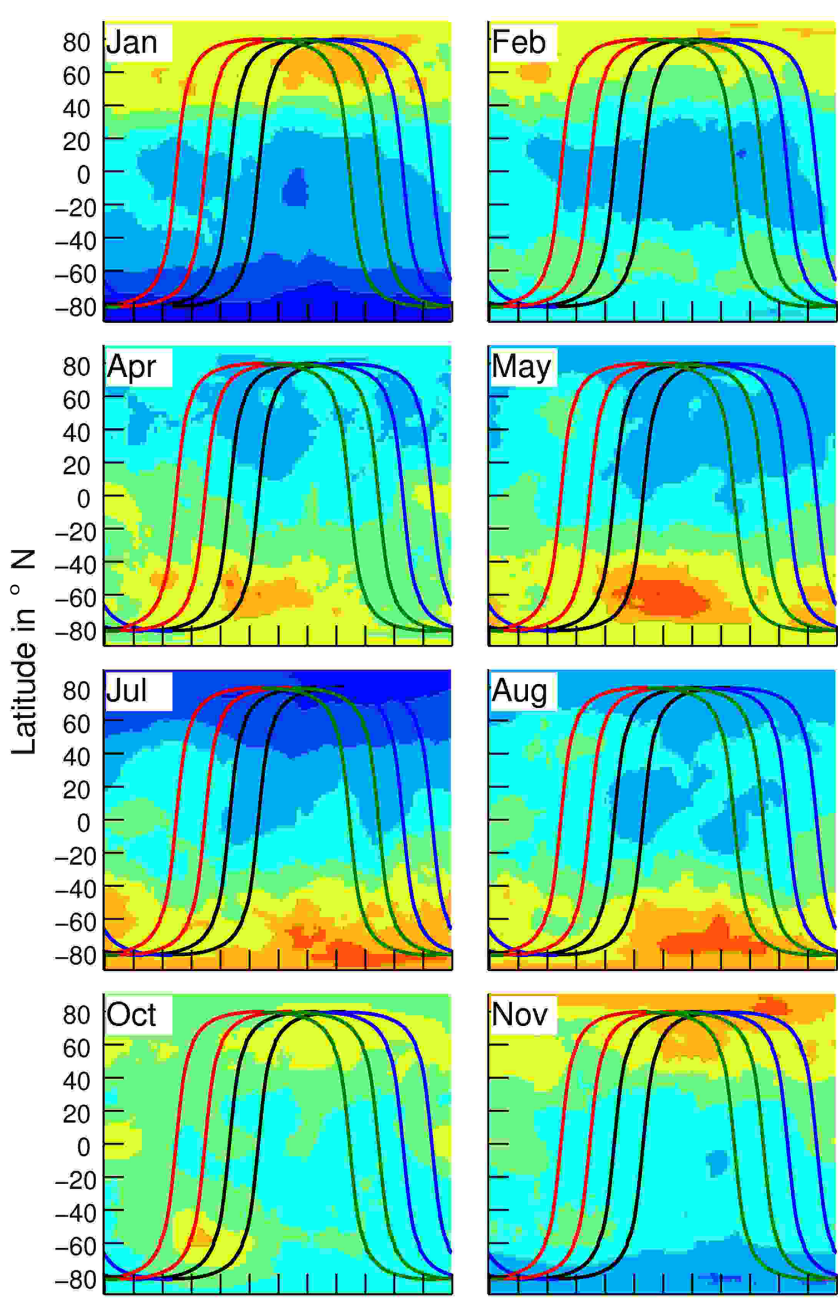

024681012141618202224
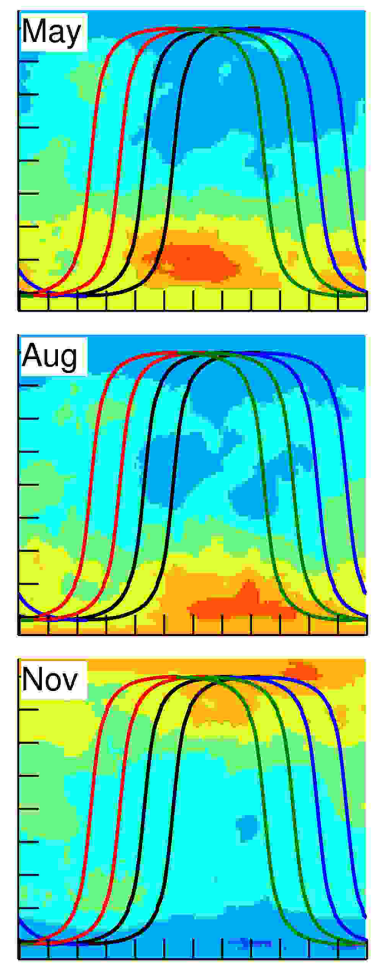

024681012141618202224024681012141618202224
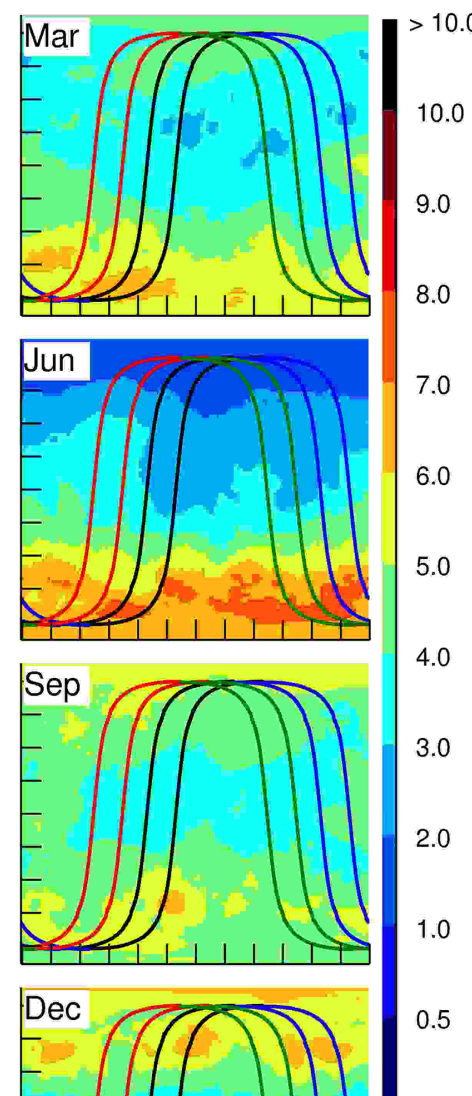

0.0

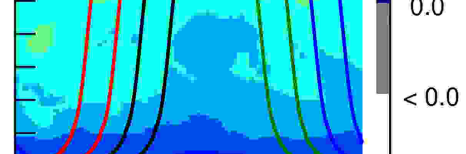

No data Local time in hour

Figure 1. WACCM vertical column densities of multi-annual monthly means during 2008-2012 for different LTs and latitudes. The WACCM data are colocated by only using the data within $\pm 1 \mathrm{~h}$ of the satellites LT. The boundaries of the colocation area are indicated by the blue lines for the ascending leg of GOMOS, by the red lines for the descending leg of OSIRIS, by the green lines for the ascending leg of OSIRIS and by the black lines for the SCIAMACHY dayglow measurements as well as for the GOMOS descending leg.

uous input. The Jupiter-family comets have orbits with periods of less than 20 years. Their current orbits are dominated by the gravitational field of Jupiter and are contained within or do not extend much beyond the orbit of Jupiter (see, e.g, Levison (1996) for a classification of comets). Additionally, the Earth passes comet trails of sublimating short-period comets, orbiting the Sun with typical periods of around 100 years, which cause meteor showers at certain periods during the year. This highly varying input, however, does not significantly increase the densities of the metal layers (see, e.g., Correira et al., 2010). The meteoroids that enter the Earth's atmosphere have geocentric speeds between 11.5 and $72.5 \mathrm{~km} \mathrm{~s}^{-1}$ and a mass distribution between $10^{-13}$ and $10^{-4} \mathrm{~kg}$, with current estimations from Nesvorný et al. (2010), Love and Brownlee (1993) and Fentzke and Janches
(2008) showing a maximum on the order of magnitude of $10^{-9}$ to $10^{-7} \mathrm{~kg}$ (see Carillo-Sánchez et al. (2015) for a comparison and detailed discussion on this issue). The ablation process (see, e.g., McNeil et al., 1998; Vondrak et al. (2008)) takes place at altitudes between 80 and $125 \mathrm{~km}$, resulting in the deposition of metallic atoms such as sodium $(\mathrm{Na})$, magnesium $(\mathrm{Mg})$, iron $(\mathrm{Fe})$, potassium $(\mathrm{K})$, calcium $(\mathrm{Ca})$, nickel (Ni) and others in the MLT. At the upper edge of the metal layers (above $90 \mathrm{~km}$ ) the metal atoms are ionized. Throughout the whole layer, especially at the bottom, the metals react to form molecular species such as carbonates, hydroxides and oxides (see, e.g., Plane et al., 2015). These molecules further are involved in chemical processes and produce condensation nuclei for the formation of particles eventually resulting in meteoric smoke particles (see, e.g., Hunten et al., 
1980; Kalashnikova et al., 2000; Saunders and Plane, 2006; Havnes and Næsheim, 2007; Hervig et al., 2012). These meteoric smoke particles are thought to play a significant role in the formation of noctilucent clouds (see, e.g., Rapp and Thomas, 2006) in the summer polar mesosphere and for aerosols and clouds in the stratosphere (see, e.g., Murphy et al., 1998; Voigt et al., 2005; Curtius et al., 2005). However, to quantify the impact of meteoric smoke on the middle atmosphere, it is important to understand the changes in chemical composition of the incoming particles during their entry into the Earth's atmosphere (e.g., Rudraswami et al., 2016) and how much meteoric material is on average deposited into the Earth's atmosphere. The rate of daily influx of meteoric material into the upper atmosphere has a large uncertainty, with estimates varying between 1 and $300 \mathrm{tday}^{-1}$ (see, e.g., Table 1 of Plane, 2012). The current best estimate for the meteoric influx is given by Carillo-Sánchez et al. (2016) and is $43 \pm 14 \mathrm{tday}^{-1}$.

The metal layers in the MLT were first observed by Slipher (1929) (who could not prove whether the sodium is from the Earth's atmosphere or from space) by means of photometry. To date, in situ measurements of the metal layers are relatively sparse. The reason for this is that balloons are only able to fly up to $50 \mathrm{~km}$ altitude, and the atmospheric drag on satellites is too strong for stable satellite orbits in the altitude of the metal layers. Therefore, in situ measurements are only possible with rockets, which on a per-profile base are relatively expensive compared with other measurement methods and additionally can only be deployed from very few locations on Earth. In situ rocket mass spectrometer measurements of metal ions were first been reported by Johnson and Meadows (1955). Until 2002, approximately 50 flights of rocket-borne mass spectrometers probing the MLT region had occurred according to Grebowsky and Aikin (2002). Due to this lack of in situ measurements, the investigation of the mesospheric metal layers heavily relies on remote-sensing methods. Quantitative ground-based observations have been made since the 1950s with photometers measuring resonance fluorescence radiation of the metal atoms that scatter the solar radiation. On the ground, photometers were superseded in the 1970s by the lidar technique (light detection and ranging), which provides several advantages: lidars allow measuring at any time of the day, whereas photometry only operates at twilight. In the context of the metal emission lines, the Sun is not an ideal light source as its spectrum usually has a minimum of spectral radiance (formally known as Fraunhofer lines) at the metal spectral lines with a spectral structure that needs to be measured at sub-picometer resolution. This shows significant Doppler shifts and varies with time (especially strong for $\mathrm{Mg}^{+}$). In contrast to that, the lasers have a maximum intensity at the desired wavelengths and a well-known spectrum. The intensity at a certain wavelength that is needed for a good signal-to-background ratio can be achieved by using the appropriate laser. Thus, it is possible to measure metal densities not just for the ground state but also for different excited states, and from this temperatures can also be derived. An overview of the locations of recent ground-based lidar measurements is given by Plane et al. (2015) (their Fig. 11). Ground-based lidar measurements provide metal density profiles with very good vertical and temporal resolution but are stationary and limited to singular points on Earth. Thus, global coverage can only be achieved by a large network of ground stations or the use of a mobile basis like a satellite.

Only in the last decades have spaceborne spectrometer measurements provided number density profiles or column density datasets with (nearly) global coverage for continuous time periods of several years. These spaceborne spectrometers typically were on board satellites with Sun-synchronous and polar orbits and a maximum scanned latitude of up to $82^{\circ}$ that retrieved densities for $\mathrm{Mg}$ and/or $\mathrm{Mg}^{+}$(see, e.g., Joiner and Aikin, 1996; Correira et al., 2008; Scharringhausen et al., 2008; Langowski et al., 2015), K (see, e.g., Dawkins et al., 2014) and $\mathrm{Na}$ (see, e.g., Fussen et al., 2004; Casadio et al., 2007; Fan et al., 2007; Gumbel et al., 2007; Fussen et al., 2010; Hedin and Gumbel, 2011; Langowski et al., 2016). Along with the measurements, global atmospheric models for the metal layers in the MLT have been developed for Na (Marsh et al., 2013a), Fe (Feng et al., 2013), Mg (Langowski et al., 2015), K (Plane et al., 2014, Feng et al., 2015; Dawkins et al., 2015), and Si (Plane et al., 2016) atoms, molecules and ions.

The global datasets for $\mathrm{Na}$ appear to be similar, but a direct comparison of these datasets has not been carried out thus far. In this study, we compare the latest global datasets for Na obtained from Global Ozone Monitoring by Occultation of Stars (GOMOS)/Envisat, SCanning Imaging Absorption spectroMeter for Atmospheric CHartography (SCIAMACHY)/Envisat and Optical Spectrograph and InfraRed Imager System (OSIRIS)/Odin measurements along with the Whole Atmosphere Community Climate Model, including the Na species (WACCM-Na), results on a global level. We have investigated the measurements and their accuracies as well as how well the model captures the observations - with one important objective being to assess the need for improvements in the measurements and the model. A more thorough discussion of the underlying atmospheric and extraterrestrial processes can be found in the references provided. In Sect. 2 the instruments and model from which the $\mathrm{Na}$ densities are retrieved are described and an error estimation for the measurements is presented. For all four datasets the Na densities are available for different latitudes, altitudes and times. Our investigations have focused on comparisons of the key profile characteristics of the Na layer, which includes the vertical column densities (VCDs; Sect. 3), the centroid altitude of the profile (Sect. 4), as well as the profile width in the form of the Full Width at Half Maximum (FWHM; Sect. 5). Finally, the key results of this comparison are summarized in Sect. 7. 

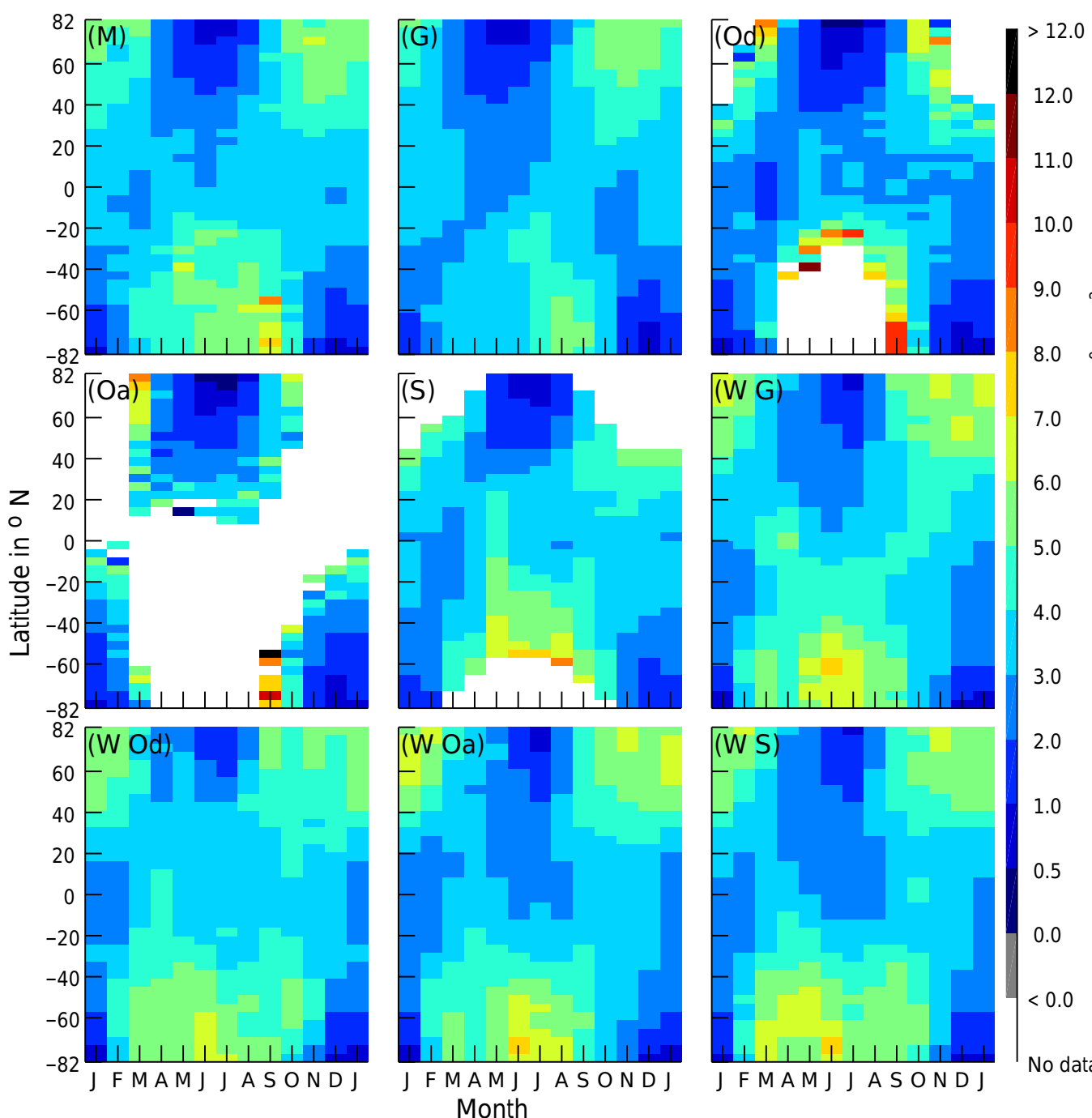

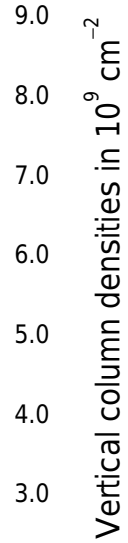

2.0

1.0

0.5

0.0

$<0.0$

No data

Figure 2. 2008-2012 multi-annual monthly mean vertical Na column densities between $76 \mathrm{~km}$ and $106 \mathrm{~km}$ altitude from different instruments and models. Ensemble mean (M), GOMOS (G), OSIRIS descending leg (Od), OSIRIS ascending leg (Oa), SCIAMACHY dayglow (S), WACCM colocated with the LT of ascending leg of GOMOS (W G), WACCM colocated with the LT of the descending leg of OSIRIS (W Od), WACCM colocated with the LT of the ascending leg of OSIRIS (W Oa), WACCM colocated with the dayglow measurements of SCIAMACHY and the descending leg of GOMOS (W S).

\section{Instruments and model information}

In this section basic information on the involved instruments and techniques is provided. However, the focus of this study shall be on the comparison of the datasets, so that the instruments and techniques, which are well documented by Fussen et al. (2010), Gumbel et al. (2007) and Langowski et al. (2016) are only briefly described. In addition, information on the errors of the different datasets is provided, which is useful when comparing different datasets.

\subsection{GOMOS}

In this study we use calculated Na densities using the model formulae given by Fussen et al. (2010) (as we do not use the actual measurement results we will use the terms GOMOS or GOMOS climatology in the following when we mean the results of these model formulae). These formulae are derived from fits to the GOMOS measurements, i.e., the retrieved data products during the period of 2002 to 2008. GOMOS flew on board the European Space Agency's (ESA) satellite Envisat, which was launched into space on 28 February 2002. Envisat flies on a Sun-synchronous orbit at around $800 \mathrm{~km}$ altitude, crossing the Equator from north to south at around 10:00 local solar time (LT), and from south to north at around 22:00 LT. Within $\pm 60^{\circ}$ latitude the LT varies within $\pm 1 \mathrm{~h}$ from the equator-crossing time. For the descending part of the orbit, at which the satellite flies from north to south, LT shifts to later hours in the north and earlier hours in the south. 
One orbit takes approximately $100 \mathrm{~min}$, which corresponds to roughly 14.5 orbits per day. In April 2012, the communication with Envisat was abruptly interrupted, and it was not possible to reestablish contact.

GOMOS was one of the first instruments to routinely exploit the principle of stellar occultation (see, e.g., Kyrölä et al., 2004; Bertaux et al., 2004) and allowed the first reported global measurement of the upper-atmospheric $\mathrm{Na}$ layer with a single instrument in 2003 (Fussen et al., 2004). The telescope system connected to the GOMOS spectrometer channels is able to track stars. The measurement principle is to measure the radiation of a star with and without the Earth's atmosphere between the star and the instrument to determine how much radiation is absorbed and scattered in the Earth's atmosphere. This is achieved for around 20 to 40 occultation measurement sequences per orbit, in which a star is followed from a tangent altitude of about 10 to $150 \mathrm{~km}$, at daylight and under night conditions, which sums up to around 550000 star occultations from 2002 to 2008. The absorption features of the $\mathrm{Na} \mathrm{D}$ lines at $589 \mathrm{~nm}$ are used to retrieve $\mathrm{Na}$ number densities. A DOAS (differential optical absorption spectroscopy) technique is used to retrieve slant path optical thicknesses, from which the Na number densities are derived. Details on the most recent version of the retrieval algorithm are given by Fussen et al. (2010). In the context of this study it should be noted that dark limb measurements during night conditions have a larger number of occultations with a higher statistical significance than the bright limb measurements during daylight and twilight conditions. This also means that during the polar summer, for which only daylight measurements are available, the statistical significance is lower than for the other latitudes and times.

Below we reproduce the expressions by Fussen et al. (2010) (their Eqs. 8, 9 and 11 along with the parameters from Table 1). These formulae consider the most important variation effects of the $\mathrm{Na}$ density field; however, this also means that not every detail of the measurements is captured, which results in a smoother density field compared with the actual measurements. A comparison of the formulae and actual measurements is shown by Fussen et al. (2010) in their Figs. 9 and 12.

The formula for the VCD $N$ for a certain month $m$ (January is $m=0$ ) and latitude $\phi$ (in radians for Eqs. 1 and 2) is

$$
\begin{aligned}
N(m, \phi)\left[\mathrm{cm}^{-2}\right] & =t_{0}+t_{1} \cos \left(\frac{2 \pi}{12} m+t_{2}\right) \\
+ & t_{3}\left(\phi+\frac{\pi}{2}\right)\left(\phi-\frac{\pi}{2}\right) \cos \left(\frac{2 \pi}{6} m+t_{4}\right) \\
t_{i \geq 1} & =f_{i}\left(a_{0}+a_{1} \phi+a_{2} \phi^{2}+a_{3} \phi^{3}\right) \\
t_{0} & =3.28 \times 10^{9} .
\end{aligned}
$$

Table 1. Parameters for Eq. (1).

\begin{tabular}{llrrrr}
\hline$i$ & $f_{i}$ & $a_{0}$ & $a_{1}$ & $a_{2}$ & $a_{3}$ \\
\hline 1 & $1 \times 10^{9}$ & 0.1282 & 1.549 & 0.1780 & 0.03511 \\
2 & 1 & 0.4017 & 0.8216 & -0.1282 & -0.2980 \\
3 & $1 \times 10^{9}$ & -0.2630 & 0.1121 & 0.6355 & -0.3566 \\
4 & 1 & -1.5635 & -3.0526 & 1.3802 & 1.7637 \\
\hline
\end{tabular}

The parameters in Eq. (1) are given in Table 1. This formula considers a constant component $t_{0}$, a yearly cycle and a semi-annual cycle. The annual cycle is most pronounced in the polar region, and its phase and amplitude are determined by the parameters $t_{1}$ and $t_{2}$. The semi-annual cycle, whose amplitude and phase are determined by the parameters $t_{3}$ and $t_{4}$, is most pronounced in the equatorial region. The different $t_{i}$ are third-order polynomials in latitude $\phi$. The fit uncertainty is about $\delta N \approx 0.81 \times 10^{9} \mathrm{~cm}^{-2}$. The formula for the peak altitude $z_{\mathrm{p}}$ (which is the same as the centroid altitude for a Gaussian-shaped layer) for a certain month $m$ and latitude $\phi$ is

$$
\begin{gathered}
z_{\mathrm{p}}(m, \phi)[\mathrm{km}]=\left(91.98-0.7723 \phi^{2}\right)+\left(0.1364-0.6532 \phi^{2}\right) \\
\cos \left(\frac{2 \pi}{12} m+1.302-0.887 \phi\right) .
\end{gathered}
$$

The peak altitude $z_{\mathrm{p}}$ is highest at the Equator and on average $2 \mathrm{~km}$ lower at the poles. This is overlaid with a seasonal cycle component, which has a $160^{\circ}$ phase shift between the variation at both poles. On average a standard deviation of $1.6 \mathrm{~km}$ is observed for different latitudes and months. The profile width of the Na layer given by Fussen et al. (2010) is not determined for individual latitudes. Instead, one global FWHM is determined as FWHM $=(11.5 \pm 3.4) \mathrm{km}$ (for a Gaussian profile the parameter $\zeta$ in Fussen et al. (2010) is converted into the FWHM by multiplication with a factor $\left.\frac{\sqrt{8 \ln (2)}}{\sqrt{2 \pi}} \approx 0.94\right)$.

\subsection{SCIAMACHY}

SCIAMACHY (see, e.g., Burrows et al., 1995; Bovensmann et al., 1999) also flew on board Envisat, which was described in Sect. 2.1. SCIAMACHY made measurements in the following viewing geometries: nadir, limb, and both solar and lunar occultation, of which the limb MLT measurements were used to retrieve $\mathrm{Na}$ densities from resonance fluorescence of the $\mathrm{Na} \mathrm{D}$ lines at $589 \mathrm{~nm}$ wavelength. The radiation source to trigger the resonance fluorescence is the Sun, so only the sunlit part of the orbit can be observed with this method. However, a method to retrieve Na from the SCIAMACHY nightglow measurements has recently been developed by von Savigny et al. (2016), but it is still in a preliminary phase and is not considered in this study.

$\mathrm{Na}$ densities were retrieved from both $\mathrm{D}$ lines, and the arithmetic average of both is used in this study. The 

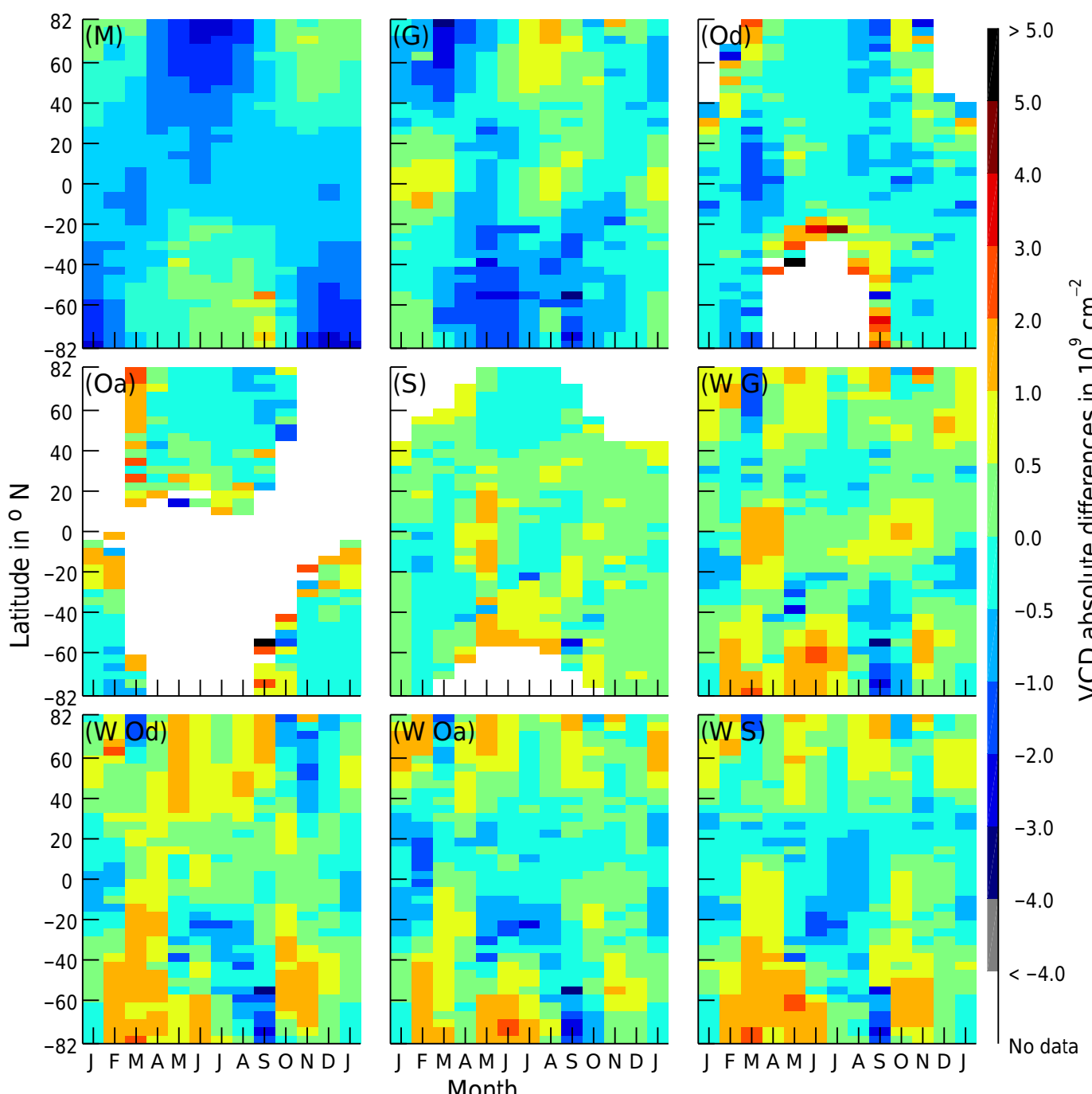

Figure 3. Absolute vertical column density differences of the individual instrument/model results compared to the ensemble mean. The panels are for the same results as in Fig. 2. The upper left panel shows the ensemble mean with the same color bar as in Fig. 2.

limb MLT measurements of SCIAMACHY were performed roughly every 2 weeks from 2008 to 2012 for 15 consecutive orbits, which corresponds to roughly 1 day of consecutive limb MLT scans. This resulted in 83 days of limb MLT measurements, which were used for the Na number density retrieval. Na number densities were retrieved from daily zonally averaged data, and from this multi-annual averages for each month were formed. Each limb MLT scan consists of $30 \mathrm{limb}$ measurements with tangent altitudes between 50 and $150 \mathrm{~km}$ and with a vertical step size of around $3.3 \mathrm{~km}$. The densities are calculated on a grid with a vertical spacing of $1 \mathrm{~km}$; however, the vertical resolution is about $4.5 \mathrm{~km}$ (see, e.g., Roscoe and Hill, 2002). The retrieval grid uses 40 latitude bins between $82^{\circ} \mathrm{N}$ and $82^{\circ} \mathrm{S}$ for the descending part of the orbit, which corresponds to a latitudinal sampling of roughly $4.1^{\circ}$ latitude. More details on the retrieval of the
SCIAMACHY dayglow Na dataset are described by Langowski et al. (2016).

The statistical error of the vertical profiles is roughly $10 \%$ at the peak altitude and is similar for the VCD. However, as $\mathrm{Na}$ is retrieved independently from both $\mathrm{D}$ lines, both individual results can be compared, which was done in Langowski et al. (2016). For most latitudes and months the relative differences between the $\mathrm{Na} \mathrm{D}_{1}$ and $\mathrm{Na}_{2}$-line results are within $\pm 10 \%$. However, the differences are larger at the highest latitudes during the southern hemispheric winter, with absolute differences of the VCDs of up to $3 \times 10^{9} \mathrm{~cm}^{-2}$, which corresponds to a relative difference of $40 \%$. For this study, we use the arithmetic mean of the densities from the $D_{1}$ and the $D_{2}$. With respect to the differences this means that the difference of the mean to the two individual density fields is half as large as the difference between the two individual density fields. Errors for the centroid altitude and 

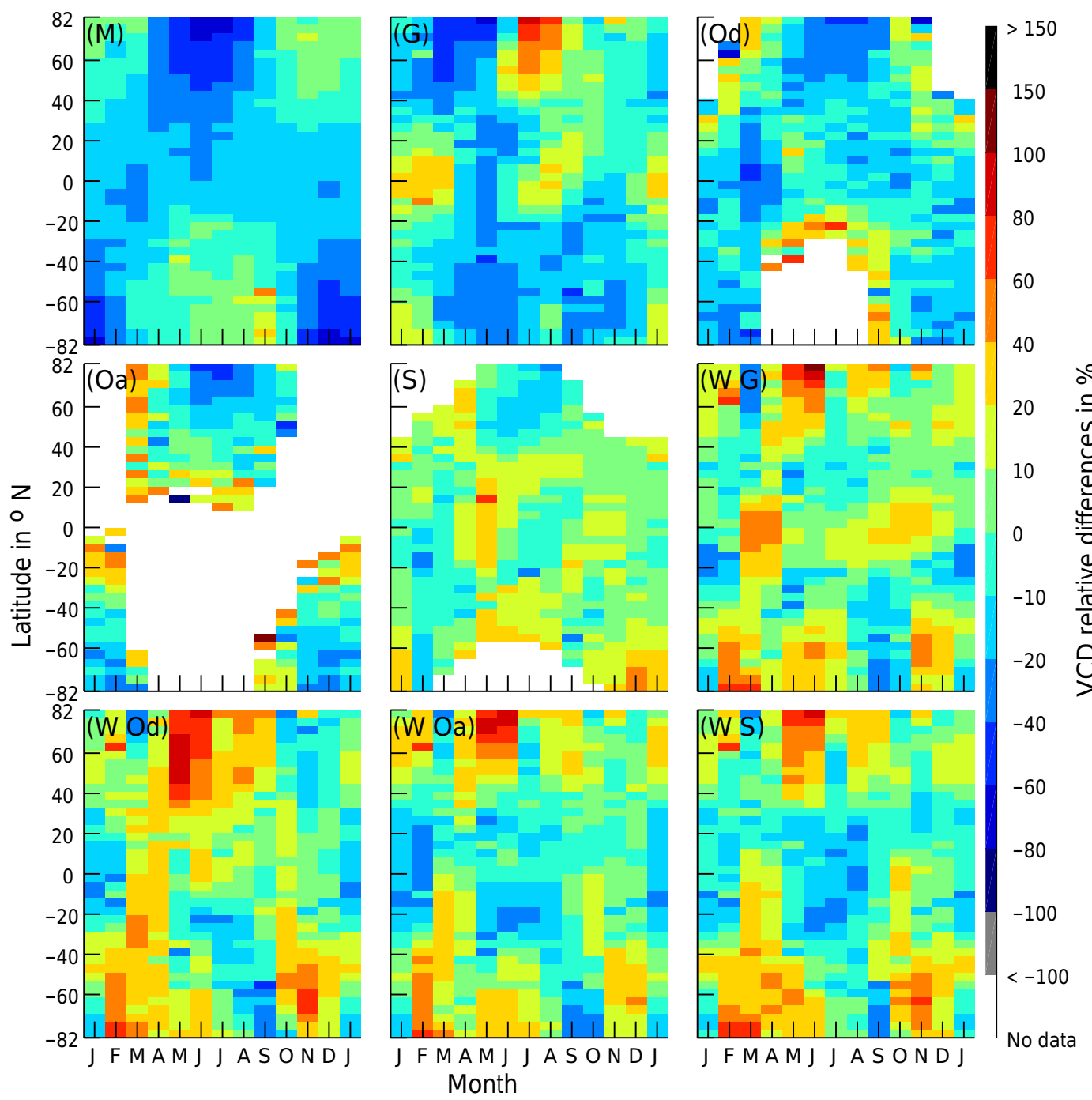

Figure 4. Relative vertical column density differences of the individual instrument/model results compared to the ensemble mean. The panels are for the same results as in Fig. 2. The upper left panel shows the ensemble mean with the same color bar as in Fig. 2.

FWHM are not provided by Langowski et al. (2016) but are estimated to be less than $1 \mathrm{~km}$. One systematic error source when determining the centroid altitude is an error in the determination of the tangent altitude of the measurements used. Bramstedt et al. (2012) showed that the tangent altitude information used in this study is accurate within a few hundred meters. This is a significant improvement compared to the initial phase of the SCIAMACHY mission, where errors were up to $5 \mathrm{~km}$ (von Savigny et al., 2005).

\subsection{OSIRIS}

OSIRIS (see, e.g., Llewellyn et al., 2004) is one of two instruments located on board the Odin satellite. Launched on a START-1 rocket on 20 February 2001 from Svobodny, Russia, Odin is a still-operational dual-purpose astronomy and aeronomy mission, designed and managed by a Swedish,
Canadian, Finnish and French consortium. The Odin satellite flies at approximately $600 \mathrm{~km}$ altitude in a Sun-synchronous, polar orbit with an inclination angle of $97.8^{\circ}$, resulting in coverage extending between $82^{\circ} \mathrm{N}$ and $82^{\circ} \mathrm{S}$. Completing approximately 15 orbits per day, the satellite has two local Equator-crossing times at 06:00 and 18:00 LT on the descending and ascending nodes, respectively. Due to orbital drift, over time these Equator-crossing times have become progressively later and are now closer to 06:50 and 18:50 LT. The OSIRIS instrument measures limb-scattered sunlight across the wavelength range $280-810 \mathrm{~nm}$, with a spectral sampling of $0.4 \mathrm{~nm}$ and spectral resolution of $1 \mathrm{~nm}$. The satellite performs limb scans between 5 and $110 \mathrm{~km}$, with a typical height resolution of $1.5-2 \mathrm{~km}$ within the mesosphere, and the instrument field-of-view is approximately $1 \mathrm{~km}$ vertically and $40 \mathrm{~km}$ horizontally when mapped onto the atmospheric limb at the tangent point. As the observation of solar- 

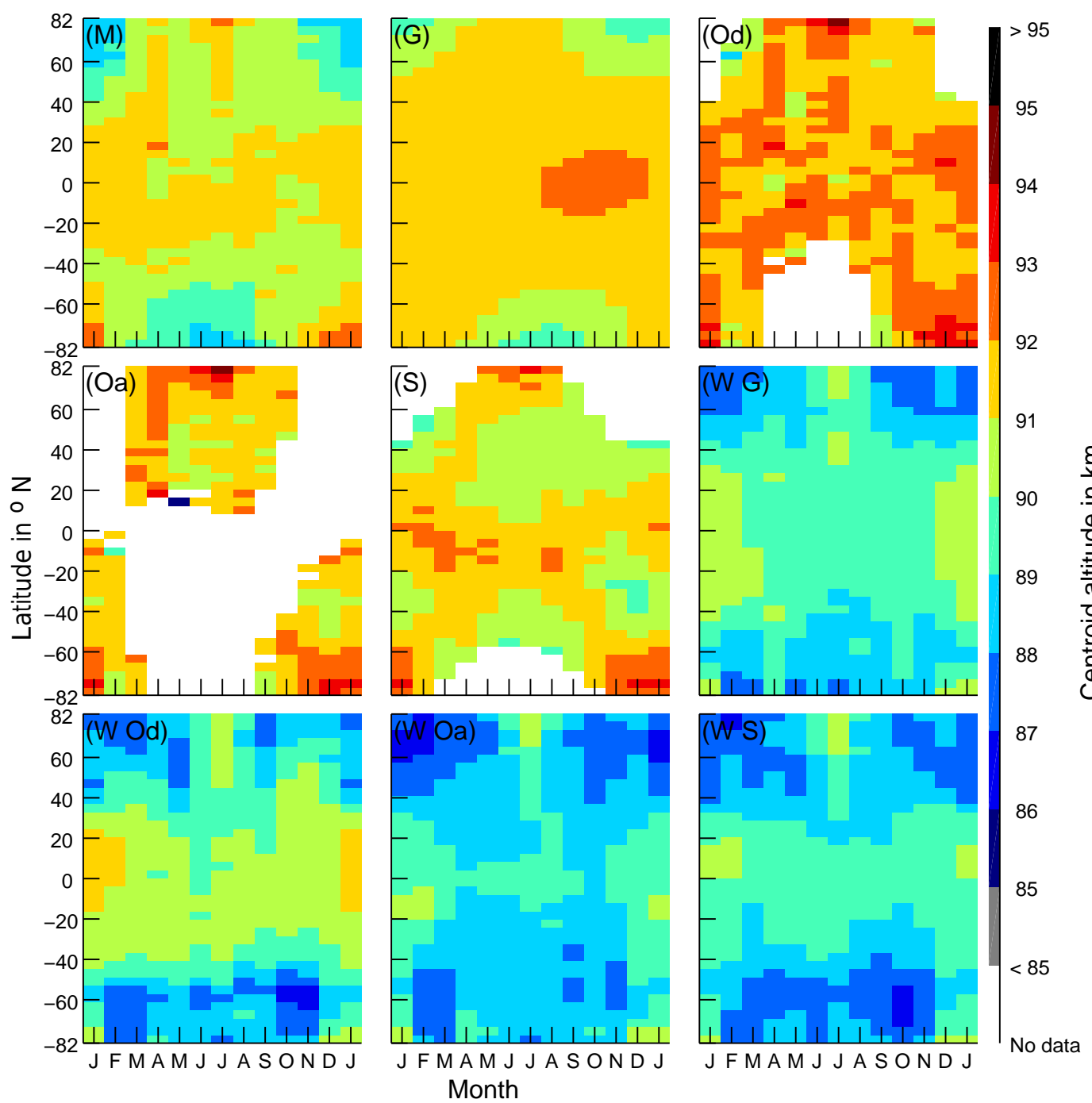

Figure 5. 2008-2012 multi-annual monthly mean Na layer centroid altitude from different instruments and models. Ensemble mean (M), GOMOS (G), OSIRIS descending leg (Od), OSIRIS ascending leg (Oa), SCIAMACHY dayglow (S), WACCM colocated with the LT of the ascending leg of GOMOS (W G), WACCM colocated with the LT of the descending leg of OSIRIS (W Od), WACCM colocated with the LT of the ascending leg of OSIRIS (W Oa), WACCM colocated with the dayglow measurements of SCIAMACHY and the descending leg of GOMOS (W S).

induced resonance fluorescence relies on daylight conditions, there is limited coverage during the winter hemisphere's polar night at middle to high latitudes. The OSIRIS Na retrieval scheme was developed by Gumbel et al. (2007) and is an optimal estimation method after Rodgers (2000) which uses a forward model to convert OSIRIS-observed limb radiances of the $\mathrm{Na} \mathrm{D}$-line resonance scattering at $589 \mathrm{~nm}$ into vertically resolved Na number densities. The observed spectra are modeled by integrating the radiation scattered toward the instrument along the line of sight in a spherical atmosphere, with background temperature and density profiles taken from the Mass Spectrometer Incoherent Scatter atmospheric model (see, e.g., Hedin, 1991) and European Centre for Medium-Range Weather Forecasts (ECMWF ERA-
Interim) reanalyses (see, e.g., Dee et al., 2011). The OSIRIS $\mathrm{Na}$ dataset consists of vertical number density profiles between 75 and $110 \mathrm{~km}$, with a vertical resolution of $2 \mathrm{~km}$ and a typical uncertainty of $10 \%$.

\subsection{WACCM-Na}

For this study we simulated the Na species during the period of 2008-2012 using an updated version of WACCM-Na, which was originally developed by Marsh et al. (2013a). In the study we used version 4 of WACCM (see, e.g., Marsh et al., 2013b) with the inclusion of the Na chemistry (see Marsh et al., 2013a) and a few updated reactions based on the recent work in Plane et al. (2015) and Gómez Martín 

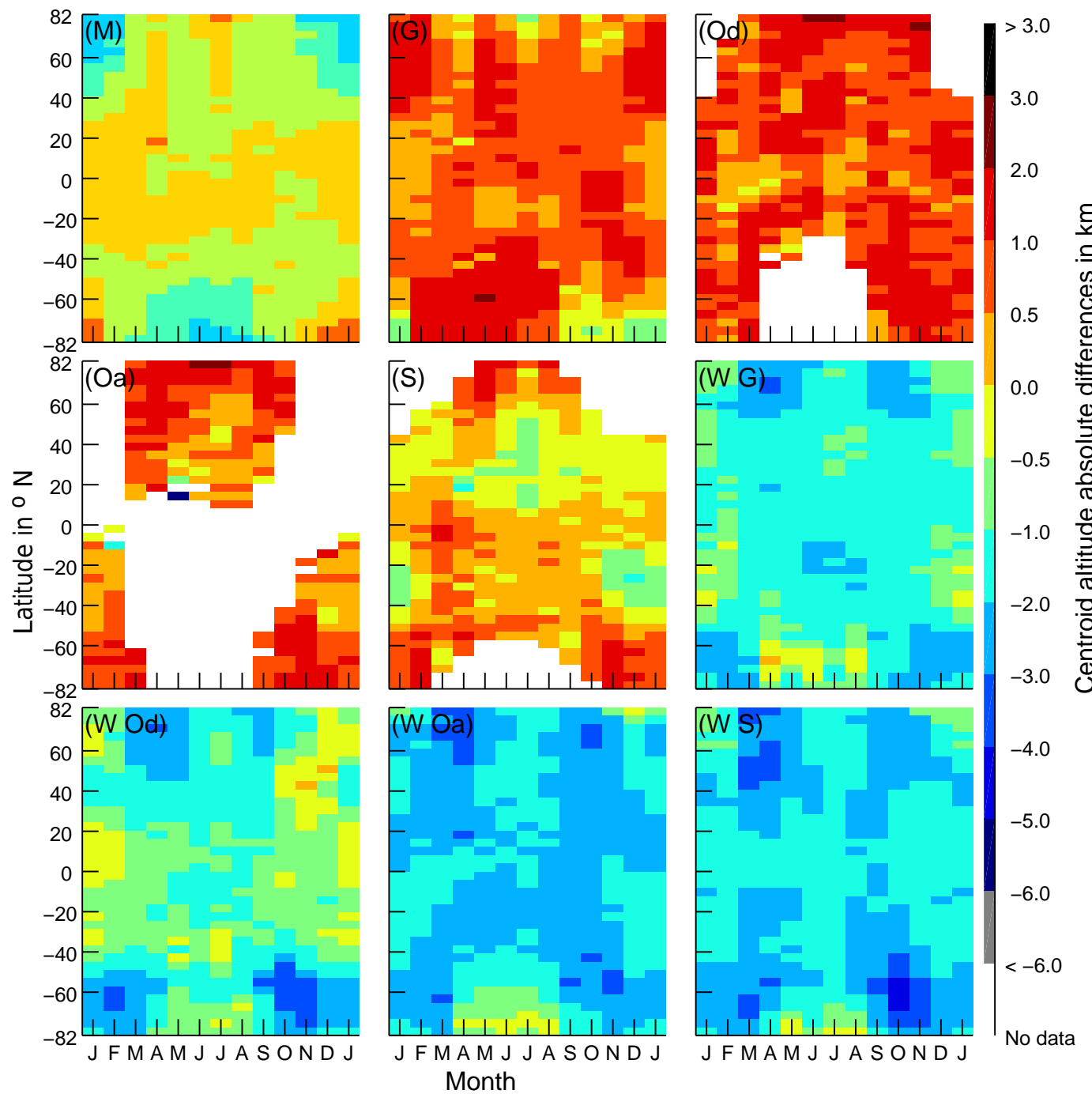

Figure 6. Absolute centroid altitude differences between the individual instrument/model and the ensemble mean. The panels are for the same results as in Fig. 5. The upper left panel shows the ensemble mean with the same color bar as in Fig. 5.

et al. (2016) under the numerical framework of the NCAR Community Earth System Model, version 1 (CESM1; see, e.g., Hurrell et al., 2013). WACCM is a high-top coupled chemistry-climate model with an upper boundary at $6.0 \times$ $10^{-6} \mathrm{hPa}$, which corresponds to an altitude of $\approx 140 \mathrm{~km}$ and integrates atmospheric chemistry and physics from the troposphere up to the lower thermosphere with a detailed description of mesospheric and lower-thermosphere processes (see, e.g., Marsh et al., 2007) as well as detailed formulations of radiation, planetary boundary layer turbulence, cloud microphysics and aerosols (see, e.g., Mills et al., 2016). The model horizontal resolution is $1.9^{\circ} \times 2.5^{\circ}$, with a vertical resolution in the MLT of less than $500 \mathrm{~m}$, which is identical to Viehl et al. (2016), by increasing the hybrid sigma-pressure vertical coordinate from 88 to 144 levels, using the same method as Merkel et al. (2009). WACCM is nudged with specified dynamics using meteorological fields from the NASA Global
Modeling and Assimilation Office Modern-Era Retrospective Analysis for Research and Applications (MERRA; see, e.g., Rienecker et al., 2011) below $60 \mathrm{~km}$. The Prandtl number was set to 2 here, which is suggested by other MLT studies, e.g., Garcia et al. (2016). The meteoric input function for $\mathrm{Na}$ is described in Marsh et al. (2013a). WACCM-Na, in the following just called WACCM, satisfactorily reproduces the seasonal cycle of the Na layer (column density, peak concentration, layer height, and top and bottom scale heights) when compared with satellite and lidar observations (see, e.g., Marsh et al., 2013a; Dunker et al., 2015). The modeled global fields are saved daily at midnight UT during the simulation period for the data used in this study. 

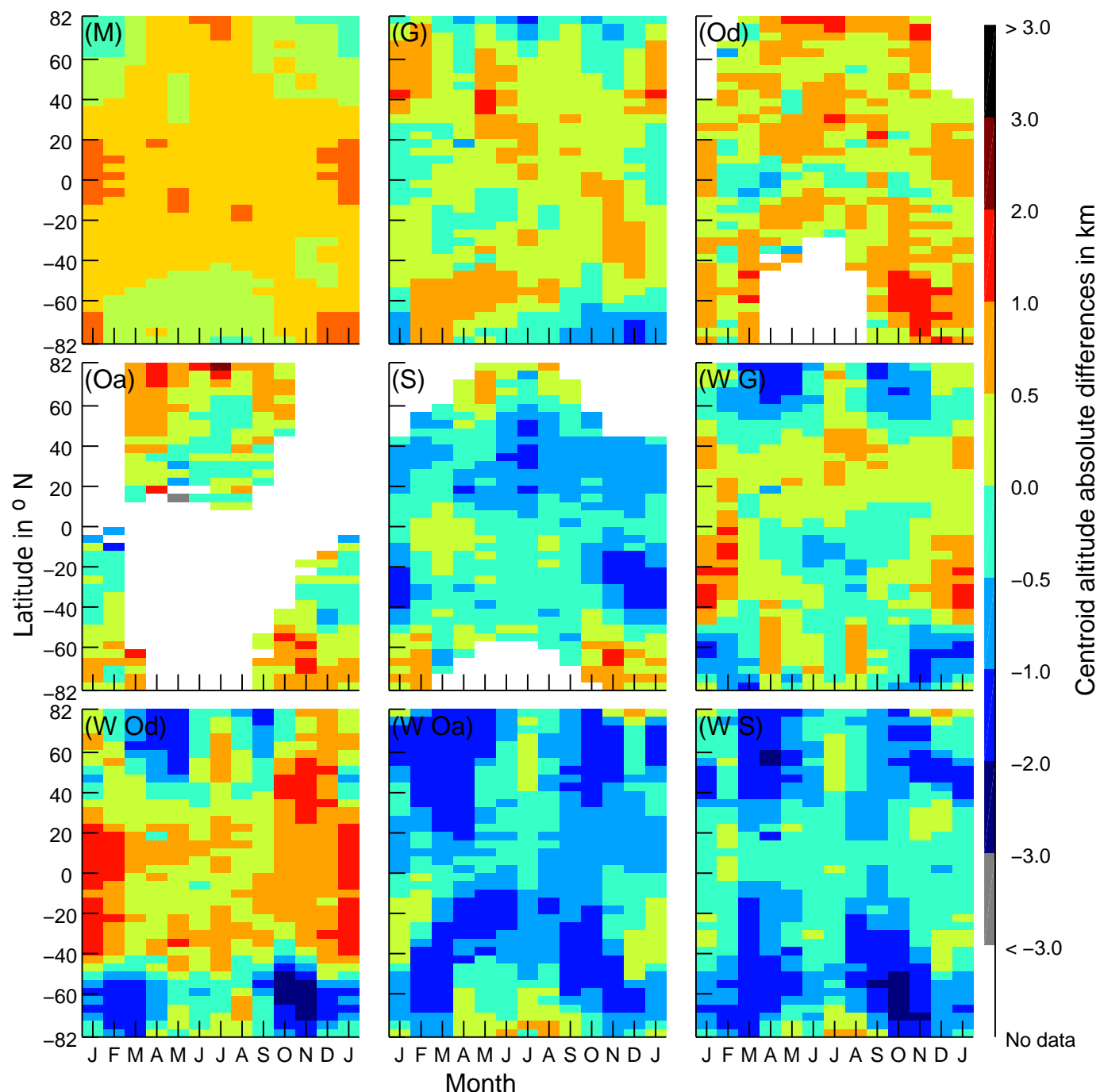

Figure 7. Absolute centroid altitude differences of the individual instrument/model results compared to the ensemble mean with WACCM centroid altitudes shifted $2 \mathrm{~km}$ upwards. The panels are for the same results as in Fig. 5. The upper left panel shows the ensemble mean with the same color bar as in Fig. 5.

\subsection{Homogenization of the datasets for comparison}

As the different datasets cover different time, latitude and altitude ranges, the datasets have to be colocated and interpolated. The WACCM LT is colocated with the different satellite LTs by applying the following steps: first the global output of WACCM at 00:00 UTC is saved. It is assumed that different longitudes correspond to different LTs. To colocate WACCM to the satellite instruments, only the data within $\pm 1 \mathrm{hLT}$ of the satellite instruments are filtered, and zonal averages are formed for the filtered WACCM data.

This LT colocation with the different satellite experiments is shown in Fig. 1.

As the model and measurement results are calculated for different latitude and altitude grids, the data are colocated with the instruments with the coarsest grid resolu- tion. The degrading of the resolution of the better-resolved dataset to the resolution of the dataset with the coarsest resolution is done by forming weighted means. For example, for the coarse altitude interval at $76 \mathrm{~km}$, which spans from 75 to $77 \mathrm{~km}$, while the altitude interval of the finer SCIAMACHY grid is $1 \mathrm{~km}$, the following weighting formula is used: $n_{\text {coarse }}(76 \mathrm{~km})=\left(0.5 n_{\text {fine }}(75 \mathrm{~km})+n_{\text {fine }}(76 \mathrm{~km})+\right.$ $\left.0.5 n_{\text {fine }}(77 \mathrm{~km})\right) / 2$. As the $2 \mathrm{~km}$ sampling is still finer than the resolution of SCIAMACHY, which is about $4.5 \mathrm{~km}$, the resolution is not decreased due to the averaging, which also applies to the other data. As the SCIAMACHY Na dataset only includes 83 individual days from 2008 to 2016, data from the same days have been used from the WACCM and OSIRIS datasets to form multi-annual monthly means. This also means that, due to the data reduction, fewer data for WACCM and OSIRIS are used for the monthly means 

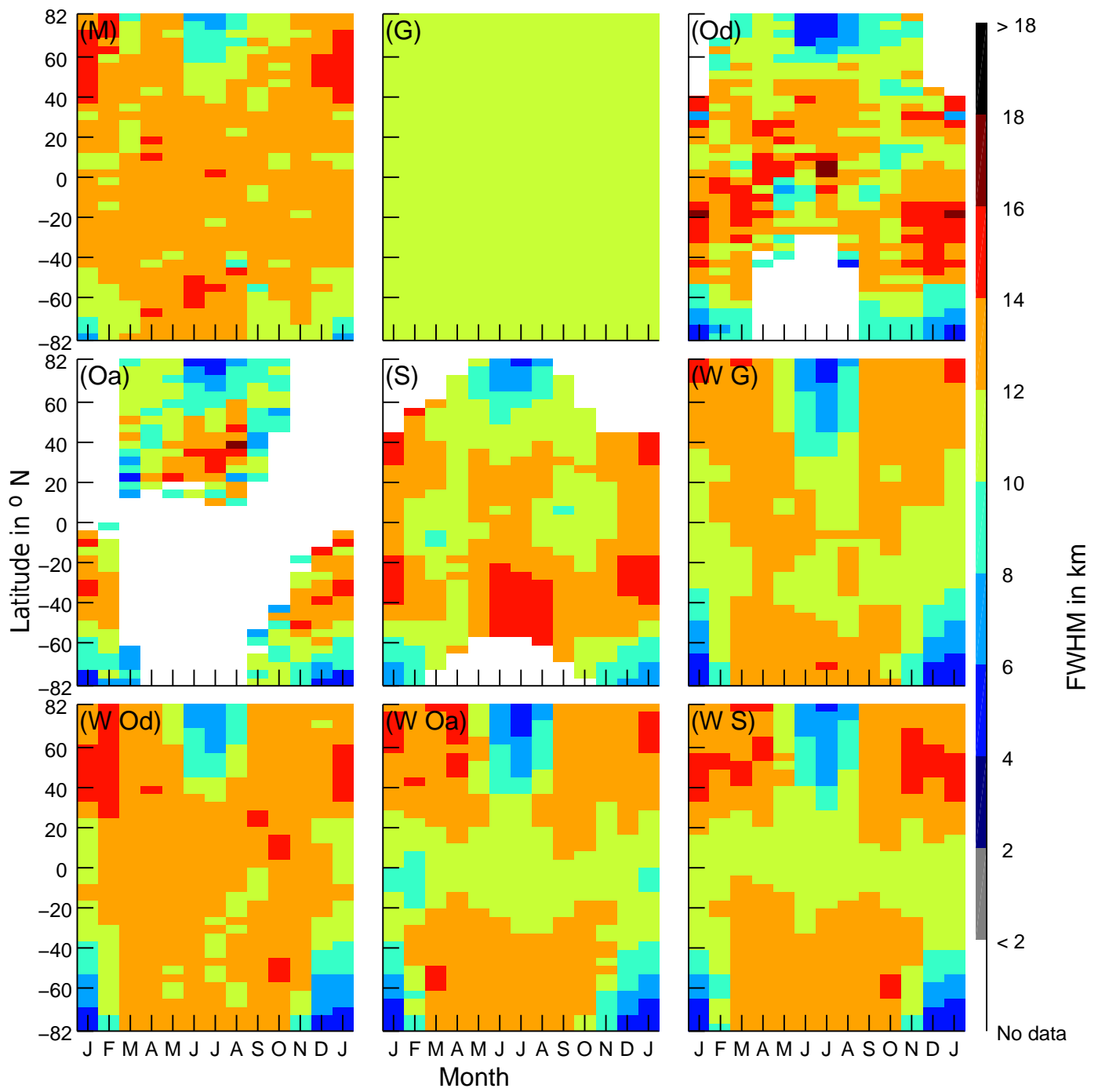

Figure 8. 2008-2012 multi-annual monthly mean Na layer full width at half maximum from different instruments and models. Ensemble mean (M), GOMOS (G), OSIRIS descending leg (Od), OSIRIS ascending leg (Oa), SCIAMACHY dayglow (S), WACCM colocated with the LT of ascending leg of GOMOS (W G), WACCM colocated with the LT of the descending leg of OSIRIS (W Od), WACCM colocated with the LT of the ascending leg of OSIRIS (W Oa), WACCM colocated with the dayglow measurements of SCIAMACHY and the descending leg of GOMOS (W S).

(2 days per month instead of 30) than are actually available, so both datasets in this study have higher noise than when using all the data available for a month. This especially applies to the near-terminator region for OSIRIS, where sometimes only one to four individual profiles are used for the averaging, which explains some outliers. The GOMOS dataset is calculated on the common altitude-latitude grid through the formulae in Sect. 2.1.

\section{Vertical column densities and differences}

To compare the different datasets with a reference dataset, an ensemble mean is formed. For the formation of the ensem- ble mean, first the arithmetic mean of the four WACCM-Na density fields for the different LTs is formed. Then, the arithmetic mean of the WACCM-Na mean and the density fields from the GOMOS measurements, SCIAMACHY measurements, and both the OSIRIS descending and ascending leg measurements is formed. If no instrument data are available at a certain latitude and time, this instrument is excluded for the averaging at this latitude and time. In the ensemble mean VCDs range from $0.5 \times 10^{9}$ to $7 \times 10^{9} \mathrm{~cm}^{-2}$ near the poles and from $3 \times 10^{9}$ to $4 \times 10^{9} \mathrm{~cm}^{-2}$ at the Equator. The sole purpose of this ensemble mean is to have a reference dataset to compare with. It does not consider a sophisticated weighting of the compared datasets. It is not necessarily better than the individual datasets, and some features, such as the LT fix- 

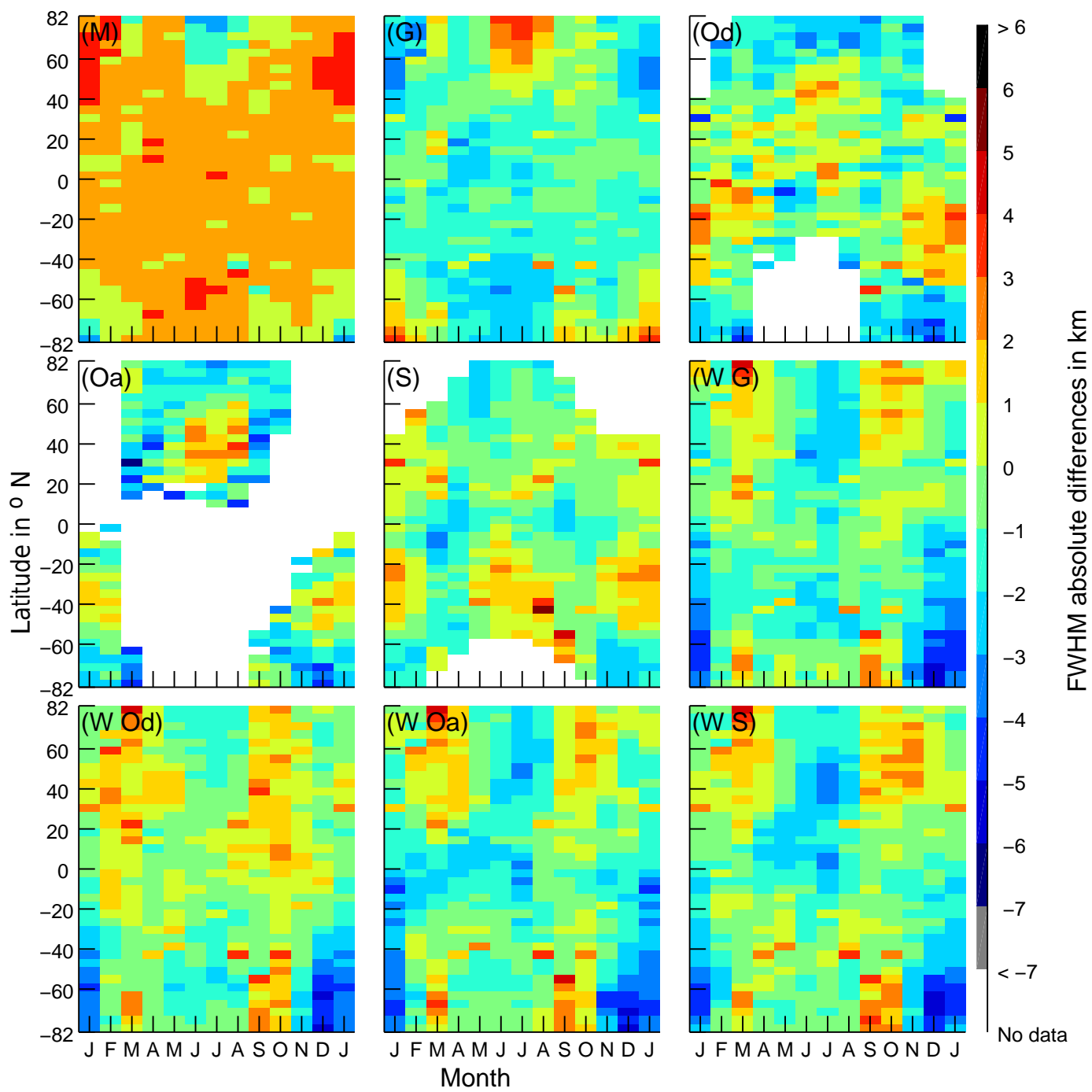

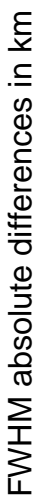

Figure 9. Absolute full width at half maximum differences of the individual instrument/model results compared to the ensemble mean. The panels are for the same results as in Fig. 8. The upper left panel shows the ensemble mean with the same color bar as in Fig. 8.

ation of the initial datasets, are lost due to the averaging. Despite these caveats the ensemble mean is presented in Table 2 for easy reproduction as a reference dataset.

Figure 2 shows the Na VCDs for the different instruments and models. The VCDs are taken for the altitudes from 76 to $106 \mathrm{~km}$. Na densities outside of this altitude region are small (below $100 \mathrm{~cm}^{-3}$ ). Figure 3 shows the absolute differences to the ensemble mean VCD, and Fig. 4 shows the relative differences to the ensemble mean VCD. Note that the upper left panels in Figs. 3 and 4 show the ensemble mean itself with the color bar as in Fig. 2, so that it easier for the reader to see the ensemble mean and the errors at the same time with the order of the panels being the same for all figures.

Overall, there is a good qualitative agreement between the different datasets; they all show a seasonal cycle with the largest amplitude in the polar region and a polar summer minimum. In the equatorial region, a semi-annual oscillation with maxima in spring and autumn is found in most of the datasets. When taking a closer look at the differences between the datasets, some measurement/model-specific differences can be found. The GOMOS Na VCD is shifted to earlier times by at least a month in the northern hemispheric summer, which leads to relatively large absolute differences even though the overall seasonal cycle is very similar to the ensemble mean. The SCIAMACHY and OSIRIS results show their largest differences to the ensemble within the near-terminator regions. SCIAMACHY also shows more pronounced differences in the southern hemispheric winter, which is also the region in which the differences of the separate retrieval of $\mathrm{Na}$ densities from the $\mathrm{D}_{1}$ and $\mathrm{D}_{2}$ lines from the SCIAMACHY measurements are largest. SCIAMACHY also shows larger vertical column densities in the equatorial region in May, which is also present in the OSIRIS descending leg results and the corresponding WACCM VCD field. 


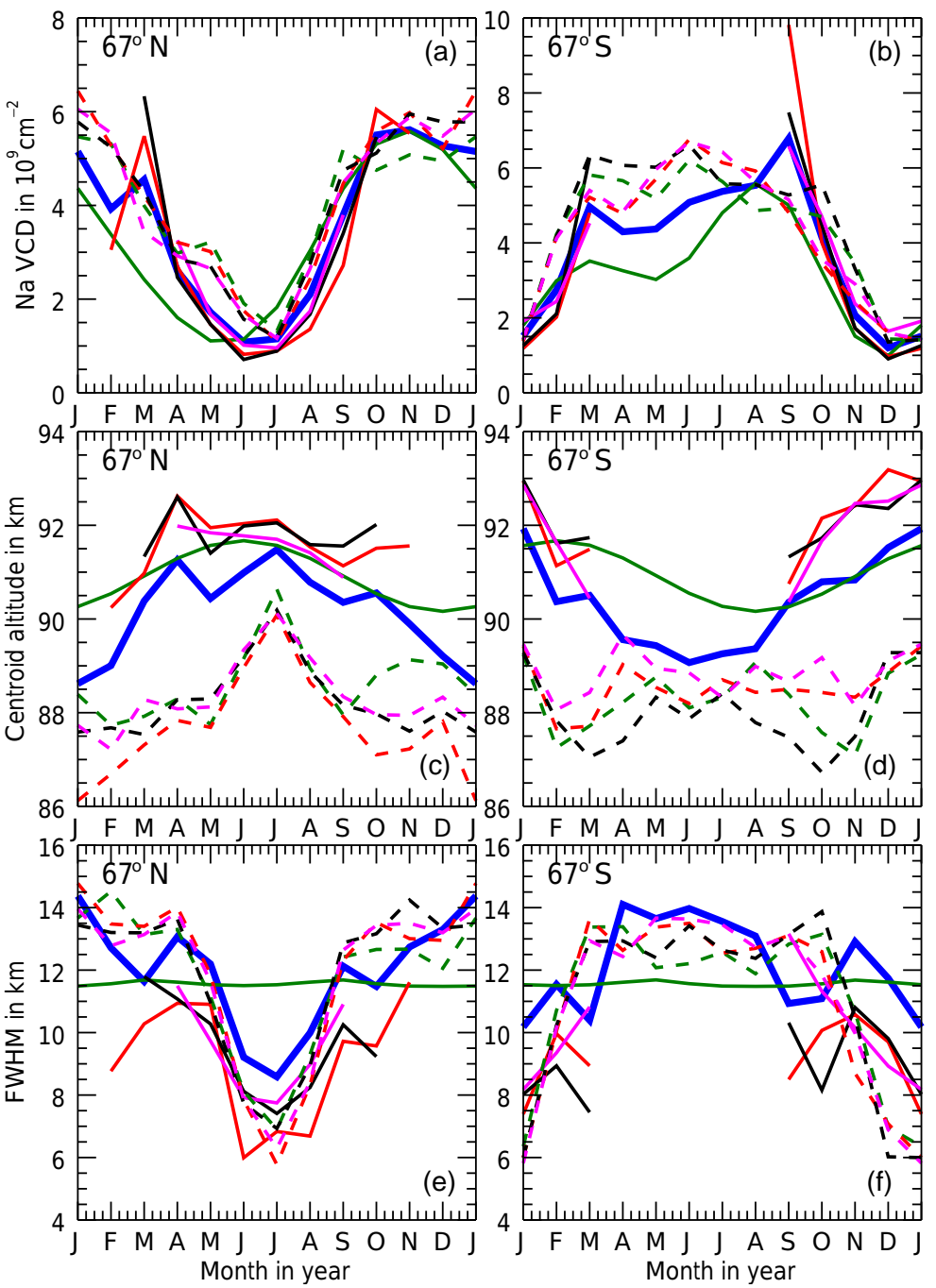

Figure 10. Vertical column density (a-b), centroid altitude (c-d) and FWHM (e-f) of the discussed datasets for $67^{\circ} \mathrm{N}(\mathbf{a}, \mathbf{c}, \mathbf{e})$ and $67^{\circ} \mathrm{N}(\mathbf{b}$, d, f). The different colors are the ensemble mean (blue), GOMOS (green, solid), OSIRIS descending leg (red, solid), OSIRIS ascending leg (black, solid) and SCIAMACHY (magenta, solid). WACCM colocated with the instruments' LT is dashed in the same color as the instruments.

However, this is missing in the GOMOS climatology, which is not colocated for the individual days and year, so this feature appears to be a seasonal speciality of the sampled days used, rather than a feature that occurs every year. In the polar summer, the satellite measurements show a slightly stronger decrease in the VCD than the corresponding WACCM measurements.

\section{Centroid altitudes and differences}

Figure 5 shows the centroid altitude of the $\mathrm{Na}$ layer for the different instruments, and Fig. 6 shows the differences of the centroid altitudes compared to the ensemble mean, except for the upper left panel, which shows the ensemble mean in the same color bar as for Fig. 5. This is for the same reason as discussed in Sect. 3.

The centroid altitudes retrieved from the satellite measurements range from 89 to $95 \mathrm{~km}$, while the $\mathrm{Na}$ centroid altitudes derived from WACCM range from $86 \mathrm{~km}$ to $92 \mathrm{~km}$ and are on average about 2 to $4 \mathrm{~km}$ lower than the measured ones. This discrepancy was already discussed by Marsh et al. (2013a) and is most likely attributed to the mesopause also being about $3 \mathrm{~km}$ lower in the WACCM simulations than in satellite observations, showing a strong dependency of the $\mathrm{Na}$ layer altitude from the thermal structure on its altitude. For the high latitudes, the centroid altitudes for all experimental datasets and also in the WACCM results are up to $4 \mathrm{~km}$ higher in the summer than in the winter, i.e., the start and end of the measurement period for the satellites with no winter coverage. While the centroid altitudes of WACCM are 
Table 2. Ensemble mean VCD for 40 latitudes within $\pm 82^{\circ} \mathrm{N}$ in $10^{9} \mathrm{~cm}^{-2}$.

\begin{tabular}{|c|c|c|c|c|c|c|c|c|c|c|c|c|}
\hline Latitude in ${ }^{\circ} \mathrm{N}$ & Jan & Feb & Mar & Apr & May & Jun & Jul & Aug & Sep & Oct & Nov & Dec \\
\hline 79.5 & 5.01 & 5.01 & 5.99 & 2.58 & 1.54 & 0.67 & 0.72 & 1.60 & 3.74 & 5.95 & 4.53 & 5.61 \\
\hline 75.4 & 4.79 & 4.79 & 5.44 & 2.43 & 1.57 & 0.82 & 0.90 & 1.83 & 3.80 & 5.53 & 5.47 & 5.39 \\
\hline 71.3 & 4.57 & 4.57 & 5.00 & 2.80 & 1.68 & 0.94 & 1.02 & 1.94 & 3.79 & 5.50 & 6.55 & 5.32 \\
\hline 67.2 & 3.93 & 3.93 & 4.55 & 2.60 & 1.72 & 1.08 & 1.15 & 2.10 & 3.80 & 5.50 & 5.62 & 5.27 \\
\hline 63.2 & 3.14 & 3.14 & 4.42 & 2.65 & 1.80 & 1.23 & 1.32 & 2.30 & 4.01 & 4.84 & 5.59 & 5.25 \\
\hline 59.1 & 4.57 & 4.57 & 4.42 & 2.50 & 1.86 & 1.39 & 1.46 & 2.44 & 3.83 & 4.83 & 5.61 & 5.30 \\
\hline 55.0 & 4.53 & 4.53 & 4.00 & 2.63 & 1.95 & 1.52 & 1.64 & 2.56 & 3.76 & 4.86 & 5.79 & 5.26 \\
\hline 50.9 & 4.54 & 4.54 & 4.00 & 2.34 & 2.04 & 1.66 & 1.81 & 2.69 & 3.89 & 4.17 & 5.53 & 5.16 \\
\hline 46.9 & 4.13 & 4.13 & 3.46 & 2.43 & 2.08 & 1.88 & 2.00 & 2.92 & 3.95 & 4.29 & 5.22 & 5.00 \\
\hline 42.8 & 4.07 & 4.07 & 3.58 & 2.42 & 2.22 & 2.08 & 2.25 & 3.06 & 3.93 & 4.42 & 5.07 & 4.59 \\
\hline 38.7 & 3.96 & 3.96 & 3.31 & 2.58 & 2.29 & 2.33 & 2.51 & 3.33 & 4.28 & 4.33 & 4.73 & 4.92 \\
\hline 34.6 & 3.82 & 3.82 & 3.65 & 2.57 & 2.47 & 2.48 & 2.73 & 3.25 & 3.71 & 4.17 & 4.65 & 4.57 \\
\hline 30.6 & 3.45 & 3.45 & 3.01 & 2.89 & 2.86 & 2.67 & 2.98 & 3.22 & 3.99 & 4.04 & 4.30 & 4.13 \\
\hline 26.5 & & & & & & & 3.02 & & & & & 3.99 \\
\hline 22.4 & 3.35 & 3.35 & 3.17 & 3.02 & 3.16 & 2.95 & 2.99 & 3.72 & 3.52 & 3.82 & 3.99 & 3.79 \\
\hline 18.3 & 3.39 & 3.39 & & & 3.25 & & 3.24 & 3.46 & 3.44 & & & 3.62 \\
\hline 14.3 & 3.30 & 3.30 & 3.38 & 3.18 & 2.65 & 2.97 & 3.16 & 3.24 & 3.39 & 3.62 & 3.53 & 3.37 \\
\hline 10.2 & 3.19 & 3.19 & 3.00 & 3.29 & 3.37 & 2.82 & 3.44 & 3.19 & 3.29 & 3.6 & 3.3 & 3.47 \\
\hline 6.1 & 3.12 & 3.12 & 2.94 & 3.27 & 3.35 & 2.83 & 3.09 & 3.11 & 3.37 & 3.6 & 3.2 & 3.24 \\
\hline 2.0 & 3.08 & 3.08 & 2.96 & 3.23 & 3.31 & 2.92 & 3.17 & 3.21 & 3.51 & 3. & 3. & 3.09 \\
\hline-2.0 & 3.25 & 3.25 & 2.93 & 3.31 & 3.31 & 3.07 & 3.20 & 3.25 & 3.48 & 3.25 & 3.1 & 2.96 \\
\hline-6.1 & 2.88 & 2.88 & 2.92 & 3.32 & 3.45 & 3.26 & 3.36 & 3.30 & 3.42 & 3.22 & 3.17 & 2.99 \\
\hline-10.2 & 2.67 & 2.67 & 2.91 & 3.29 & 3.80 & 3.57 & 3.53 & 3.44 & 3.59 & 3.34 & 3.23 & 3.04 \\
\hline-14.3 & 3.49 & 3.49 & 2.87 & 3.43 & 4.02 & 3.74 & 3.92 & 3.61 & 3.67 & 3.23 & 3.25 & 3.58 \\
\hline-18.3 & 3.24 & 3.24 & 2.97 & 3.53 & 4.14 & 4.29 & 4.24 & 3.85 & 3.80 & 3.28 & & 3.11 \\
\hline-22.4 & 3.13 & 3.13 & 3.05 & 3.57 & 4.61 & 5.28 & 5.58 & 4.13 & 4.04 & 3.36 & 3.30 & 3.17 \\
\hline-26.5 & 3.11 & 3.11 & 3.10 & & 4.82 & & 4.59 & 4.14 & 4.22 & 3.42 & & 3.40 \\
\hline-30.6 & 2.94 & 2.94 & 3.27 & 4.05 & 5.45 & 4.78 & 4.55 & 4.52 & 4.39 & 3.40 & 3.54 & 2.91 \\
\hline-34.6 & 3.06 & 3.06 & 3.38 & 3.94 & 4.62 & & 4.57 & 4.42 & 4.4 & 3.50 & 3.25 & 2.72 \\
\hline-38.7 & 3.09 & 3.09 & 3.54 & 3.93 & 6.69 & 4.86 & 4.70 & 5.02 & 4.56 & 3.46 & 3.05 & 2.58 \\
\hline-42.8 & 2.99 & 2.99 & 3.69 & 4.90 & 5.08 & 4.89 & 4.85 & 5.47 & 4.68 & 4.08 & 2.99 & 2.38 \\
\hline-46.9 & 3.12 & 3.12 & 3.93 & 4.29 & 5.14 & 5.04 & 4.95 & 5.19 & 4.99 & 3.79 & 2.85 & 2.14 \\
\hline-50.9 & 3.04 & 3.04 & 4.06 & 4.38 & 5.05 & 5.50 & 5.19 & 5.43 & 4.93 & 3.62 & 2.75 & 1.99 \\
\hline-55.0 & 3.15 & 3.15 & 4.15 & 4.51 & 5.29 & 5.86 & 5.72 & 5.79 & 8.02 & 3.52 & 2.64 & 1.80 \\
\hline-59.1 & 2.95 & 2.95 & 4.30 & 4.53 & 4.55 & 5.00 & 5.20 & 6.30 & 6.07 & 4.04 & 2.44 & 1.63 \\
\hline-63.2 & 2.90 & 2.90 & 4.61 & 4.79 & 4.47 & 5.07 & 5.31 & 5.46 & 5.86 & 3.92 & 2.23 & 1.40 \\
\hline-67.2 & 2.75 & 2.75 & 4.96 & 4.30 & 4.37 & 5.08 & 5.37 & 5.54 & 6.78 & 4.15 & 2.07 & 1.20 \\
\hline-71.3 & 2.64 & 2.64 & 4.42 & 4.32 & 4.43 & 5.24 & 5.37 & 5.60 & 6.78 & 4.22 & 2.04 & 1.03 \\
\hline-75.4 & 2.30 & 2.30 & 3.91 & 4.34 & 4.59 & 5.33 & 5.35 & 5.63 & 7.38 & 4.15 & 1.94 & 0.90 \\
\hline-79.5 & 2.05 & 2.05 & 3.52 & 4.40 & 4.79 & 5.26 & 5.39 & 5.58 & 6.66 & 4.12 & 1.77 & 0.77 \\
\hline
\end{tabular}

systematically lower, the seasonal and LT variations of the measurements appear to be well reproduced by the model. For example, in the low latitudes the profiles from descending leg measurements with OSIRIS have a higher centroid altitude than the SCIAMACHY profiles, which is a LT effect that appears also in the WACCM data. For the SCIAMACHY measurements during the summer, there is a minimum in centroid altitude at midlatitudes, while the altitude is higher at the Equator and the summer pole, which is also present in the WACCM data. For a better comparison of the data Fig. 7 shows the differences of the centroid altitudes compared to the ensemble mean when the WACCM centroid altitude is shifted $2 \mathrm{~km}$ upwards. This results in an nearly optimal agreement for most latitudes and times of WACCM with GOMOS, SCIAMACHY and the descending leg of OSIRIS when only a global shift between these datasets is considered. For the ascending leg of OSIRIS the optimal shift is around $3 \mathrm{~km}$.

\section{Profile widths and differences}

Figure 8 shows the FWHM of the different datasets, and Fig. 9 shows the differences to the ensemble mean, except for the upper left panel, which shows the ensemble mean in 
the same color bar as for Fig. 8, for the same reason as discussed in Sect. 3.

The $50 \%$ altitudes for the FWHM are found via interpolation from the sampled grid. For the GOMOS climatology the mean width for all GOMOS measurements of $11.5 \mathrm{~km}$ is used at all times and latitudes. The FWHM ranges from the sampling and resolution limit of 2 to $18 \mathrm{~km}$. For most latitudes the FWHM is between 10 and $16 \mathrm{~km}$. For the datasets in which the FWHM is determined to be latitude specific, the lowest profile width is observed in the polar summer. The WACCM model shows the largest profile widths in polar winter, which is not covered by the instruments. The LT differences between the descending leg of OSIRIS and SCIAMACHY are also present in the WACCM data, with OSIRIS showing, for example, slightly larger profile widths in the low latitudes than the SCIAMACHY data.

\section{Line plots at selected latitude}

As color plots are sometimes harder to read than line plots and the seasonal variations are strongest in the polar regions, Fig. 10 shows line plots of the VCDs, centroid altitudes and profile width for the different instruments at $67^{\circ} \mathrm{N}$ and $67^{\circ} \mathrm{S}$ for all discussed datasets.

All datasets show a summer minimum in VCD. The centroid altitudes of the four instruments agree well at $67^{\circ} \mathrm{N}$ in the northern summer. The centroid altitudes of SCIAMACHY and OSIRIS match very well at $67^{\circ} \mathrm{S}$ in the southern hemispheric summmer, while the GOMOS centroid altitude is about a $\mathrm{km}$ lower from October to January. The WACCM centroid altitudes are generally about $2 \mathrm{~km}$ lower than the measurement centroid altitudes. Due to the stronger weighting in winter, this leads to a seasonal cycle of the ensemble mean, with a summer maximum which is more pronounced than the one found in the GOMOS climatology. Only one average FWHM of the GOMOS climatology was formed. Therefore, there is no discrimination for summer, winter or latitude in these data. The other datasets show a decreased FWHM in summer in both hemispheres. With respect to the variations of the different datasets, no strong differences between the two hemispheres can be seen in the three key characteristics of the Na layer.

\section{Conclusions}

The currently available global experimental and model datasets of upper-atmospheric $\mathrm{Na}$ densities were compared in this paper, focusing particularly on the VCDs, centroid altitudes and profile widths. Overall, there is good agreement between the datasets for the VCDs. The differences are largest for measurements carried out near the terminator. The GOMOS dataset appears to be shifted by around a month ahead of the other datasets in the Northern Hemisphere. The VCDs vary from $0.5 \times 10^{9}$ to $7 \times 10^{9} \mathrm{~cm}^{-2}$ near the poles and around $3 \times 10^{9}$ to $4 \times 10^{9} \mathrm{~cm}^{-2}$ at the Equator. The absolute differences of the VCD are below $\pm 1 \times 10^{9} \mathrm{~cm}^{-2}$ for most latitudes and times and exceed $\pm 2 \times 10^{9} \mathrm{~cm}^{-2}$ only for very few elements of the density fields. The centroid altitudes of the different measurements are in good agreement and vary from 89 to $95 \mathrm{~km}$. In the polar regions the centroid altitudes are highest in the summer. The Na layer centroid altitudes modeled by WACCM are systematically 2 to $4 \mathrm{~km}$ lower than those of the measurements. However, the LT variations between the different satellite measurements are also present in the WACCM data. The FWHMs of the different datasets are in agreement, and the WACCM model reproduces the LT differences between OSIRIS and SCIAMACHY well. The FWHM is around 10 to $16 \mathrm{~km}$ for most latitudes and times; however, in the polar summer there is a thinning-out of the $\mathrm{Na}$ layer with low FWHM of around $5 \mathrm{~km}$.

Data availability. The SCIAMACHY and GOME data can be accessed from ESA: https://earth.esa.int/web/guest/data-access/ how-to-access-esa-data. OSIRIS data can be accessed here: http: //osirus.usask.ca/. The WACCM model can be accessed here: http: //www.cesm.ucar.edu/working_groups/Whole-Atmosphere/.

Competing interests. The authors declare that they have no conflict of interest.

Acknowledgements. This work was in part supported by the European Space Agency (ESA) through the MesosphEO project, by Ernst Moritz Arndt University of Greifswald and by the University of Bremen. SCIAMACHY was jointly funded by Germany (DLR), the Netherlands (NSO) and Belgium. We are indebted to ESA for providing the SCIAMACHY Level 1 data used in this study. GOMOS was an ESA-funded instrument and was developed as a joint project of Finland and France. We would like to thank both Jonas Hedin and Jörg Gumbel for providing the original OSIRIS Na retrieval code. Odin is a Swedish-led satellite project funded jointly by Sweden (SNSB), Canada (CSA and NSERC), Finland (Tekes) and France (CNES). OSIRIS is a Canadian (CSA) instrument, and we would like to extend our thanks to mission PI Doug Degenstein as a representative for the team. The WACCM-Na model work was supported by the European Research Council (project number 291332, CODITA). We would like to thank Diego Janches at NASA Goddard Space Flight Center for providing the Na meteoric input function data used in WACCM-Na. The National Center for Atmospheric Research (NCAR) is sponsored by the US National Science Foundation.

The article processing charges for this open-access publication were covered by the University of Bremen.

Edited by: M. Rapp

Reviewed by: two anonymous referees 


\section{References}

Bertaux, K. L., Hauchecorne, A., Dalaudier, F., Cot, C., Kyrölä, E., Fussen, D., Tamminen, J., Leppelmeier, G. W., Sofieva, V., Hassinen, S., Fanton d'Andon, O., Barrot, G., Mangin, A., Théodore, B., Guirlet, M., Korablev, O., Snoeijj, P., Koopman, R., and Fraisse, R.: First results on GOMOS/Envisat, Adv. Space Res., 33, 1029-1035, 2004.

Bovensmann, H., Burrows, J. P., Buchwitz, M., Frerick, J., Noël, S., Rozanov, V. V., Chance, K. V., and Goede, A. P. H.: SCIAMACHY: Mission Objectives and Measurement Modes, J. Atmos. Sci., 56, 127-150, 1999.

Bramstedt, K., Noël, S., Bovensmann, H., Gottwald, M., and Burrows, J. P.: Precise pointing knowledge for SCIAMACHY solar occultation measurements, Atmos. Meas. Tech., 5, 2867-2880, https://doi.org/10.5194/amt-5-2867-2012, 2012.

Burrows, J. P., Hölzle, E., Goede, A. P. H., Visser, H., and Fricke, W.: SCIAMACHY-scanning imaging absorption spectrometer for atmospheric chartography, Acta Astronaut., 35, 445-451, 1995.

Carillo-Sánchez, J. D.and Nesvorný, D., Pokorný, P., Janches, D., and Plane, J. M. C.: Sources of cosmic dust in the Earth's atmosphere, Geophys. Res. Lett., 43, 1197 -11986, 2016.

Carillo-Sánchez, J. D., Plane, J. M. C., Feng, W., Nesvorný, D., and Janches, D.: On the size and velocity distribution of cosmic dust particles entering the atmosphere, Geophys. Res. Lett., 42, 6518-6525, 2015.

Casadio, S., Retscher, C., Lang, R., di Sarra, A., Clemesha, B., and Zehner, C.: Retrieval of mesospheric sodium densities from SCIAMACHY daytime limb spectra, Proc. Envisat Symposium, Montreux, Switzerland, 23-27 April, 2007.

Correira, J., Aikin, A. C., Grebowsky, J. M., Pesnell, W. D., and Burrows, J. P.: Seasonal variations of magnesium atoms in the mesosphere-thermosphere, Geophys. Res. Lett., 35, 330-337, 2008.

Correira, J., Aikin, A. C., Grebowsky, J. M., and Burrows, J. P.: Metal concentrations in the upper atmosphere during meteor showers, Atmos. Chem. Phys., 10, 909-917, https://doi.org/10.5194/acp-10-909-2010, 2010.

Curtius, J., Weigel, R., Vössing, H.-J., Wernli, H., Werner, A., Volk, C.-M., Konopka, P., Krebsbach, M., Schiller, C., Roiger, A., Schlager, H., Dreiling, V., and Borrmann, S.: Observations of meteoric material and implications for aerosol nucleation in the winter Arctic lower stratosphere derived from in situ particle measurements, Atmos. Chem. Phys., 5, 3053-3069, https://doi.org/10.5194/acp-5-3053-2005, 2005.

Dawkins, E. C. M., Plane, J. C. M., Chipperfield, M. P., Feng., W., Gumbel, J., Hedin, J., Höffner, J., and Friedman, J. S.: First global observations of the mesospheric potassium layer, Geophys. Res. Lett., 41, 5653-5661, 2014.

Dawkins, E. C. M., Plane, J. C. M., Chipperfield, M. P., and Feng., W.: The near-global mesospheric potassium layer: Observation and modeling, J. Geophys. Res.-Atmos., 120, 7975-7987, 2015.

Dee, D. P., Uppala, S. M., Simmons, A. J., Berrisford, P., Poli, P., Kobayashi, S., Andrae, U., Balmaseda, M. A., Balsamo, G., Bauer, P., Bechthold, P., Beljaars, A. C. M., van de Berg, L., Bidlot, J., Bormann, N., Delsol, C., Dragani, R., Fuentes, M., Geer, A. J., Haimberger, L., Healy, S. B., Hersberg, H., Hólm, E. V., Isaksen, L., Kållberg, P., Köhler, M., Matricardi, M., McNally, A. P., Monge-Sanz, A. P., Morcrette, J.-J., Park, B.-K., Peubey,
C., de Rosnay, P., Tavolato, C., Thépaut, J.-N., and Vitart, F.: The ERA-Interim reanalysis: configuration and performance of the data assimilation system, Q. J. Roy. Meteorol. Soc., 137, 553597, 2011.

Dunker, T., Hoppe, U.-P., Feng, W., Plane, J. M. C., and Marsh, D. R.: Mesospheric temperatures and sodium properties measured with the ALOMAR Na lidar compared with WACCM, J. Atmos. Sol.-Terr. Phys., 127, 111-119, 2015.

Fan, Z. Y., Plane, J. M. C., Gumbel, J., Stegman, J., and Llewellyn, E. J.: Satellite measurements of the global mesospheric sodium layer, Atmos. Chem. Phys., 7, 4107-4115, https://doi.org/10.5194/acp-7-4107-2007, 2007.

Feng, W., Marsh, D. R., Chipperfield, M. P., Janches, D., Höffner, J., Fan, Y., and Plane, J. M. C.: A global atmospheric model of meteoric iron, J. Geophys. Res., 118, 9456-9474, 2013.

Feng, W., Höffner, J., Marsh, D. R., Chipperfield, M. P., Dawkins, E. C. M., Viehl, T. P., and Plane, J. M. C.: Diurnal variation of the potassium layer in the upper atmosphere, Geophys. Res. Lett., 42, 3619-3626, 2015.

Fentzke, J. T. and Janches, D.: A semi-empirical model of the contribution from sporadic meteoroid sources on the meteor input function observed at arecibo, J. Geophys. Res.-Space, 113, A03304, https://doi.org/10.1029/2007JA012531, 2008.

Fussen, D., Vanhellemont, F., Bingen, C., Kyrölä, E., Tamminen, J., Sofieva, V., Hassinen, S., Seppälä, Verronen, P., Bertaux, J.-L., Hauchecorne, A., Dalaudier, F., Renard, J.-B., Fraisse, R., Fanton d'Andon, O., Barrot, G., Mangin, A., Théodore, B., Guirlet, M., Koopman, R., Snoeijj, P., and Saavedra, L.: Global measurement of the mesospheric sodium layer by the star occultation instrument GOMOS, Geophys. Res. Lett., 31, L24110, https://doi.org/10.1029/2004GL021618, 2004.

Fussen, D., Vanhellemont, F., Tétard, C., Mateshvili, N., Dekemper, E., Loodts, N., Bingen, C., Kyrölä, E., Tamminen, J., Sofieva, V., Hauchecorne, A., Dalaudier, F., Bertaux, J.-L., Barrot, G., Blanot, L., Fanton d'Andon, O., Fehr, T., Saavedra, L., Yuan, T., and She, C.-Y.: A global climatology of the mesospheric sodium layer from GOMOS data during the 2002-2008 period, Atmos. Chem. Phys., 10, 9225-9236, https://doi.org/10.5194/acp10-9225-2010, 2010.

Garcia, R., López-Puertas, M., Funke, B., Kinnison, D. E., Marsh, D. R., and Qian, L.: On the secular trend of $\mathrm{CO}_{x}$ and $\mathrm{CO}_{2}$ in the lower thermosphere, J. Geophys. Res.-Atmos., 121, 3634-3644, 2016.

Gómez Martín, J. C., Garraway, S. A., and Plane, J. M. C.: Reaction Kinetics of Meteoric Sodium Reservoirs in the Upper Atmosphere, J. Phys. Chem. A, 120, 1330-1346, 2016.

Grebowsky, J. M. and Aikin, A. C.: Chapter 8 in: Meteors in the Earth's atmosphere, edited by: Murad, E. and Williams, I. P., Cambridge University Press, Cambridge, 2002.

Gumbel, J., Fan, Z. Y., Waldemarsson, T., Stegman, J., Witt, G., Llewellyn, E., She, C.-Y., and Plane, J. M. C.: Retrieval of global mesospheric sodium densities from the Odin satellite, Geophys. Res. Lett., 34, L04813, https://doi.org/10.1029/2006GL028687, 2007.

Havnes, O. and Næsheim, L. I.: On the secondary charging effects and structure of mesospheric dust particles impacting on rocket probes, Ann. Geophys., 25, 623-637, 2007. 
Hedin, A. E.: Extension of the MSIS Thermosphere Model into the middle and lower atmosphere, J. Geophys. Res., 96, 1159-1172, 1991.

Hedin, J. and Gumbel, J.: The global mesospheric sodium layer observed by Odin/OSIRIS in 2004-2009, J. Atmos. Sol.-Terr. Phys., 73, 2221-2227, 2011.

Hervig, M. E., Deaver, L. E., Bardeen, C. G., Russell III, J. M., Bailey, S. M., and Gordley, L. L.: The content and composition of meteoric smoke in mesospheric ice particles from SOFIE observations, J. Atmos. Sol.-Terr. Phys., 84-85, 1-6, 2012.

Hunten, D. M., Turco, R. P., and Toon, O. B.: Smoke and Dust Particles of Meteoric Origin in the Mesosphere and Stratosphere, J. Atmos. Sci., 37, 1342-1357, 1980.

Hurrell, J., Holland, M. M., Gent, P. R., Ghan, S., Kay, J. E., Kushner, P. J., Lamarque, J.-F., Large, W. G., Lawrence, D., Lindsay, K., Lipscomb, W. H., Long, M. C., Mahowald, N., Marsh, D. R., Neale, R. B., Rasch, P., Vavrus, S., Vertenstein, M., Bader, D., Collins, W. D., Hack, J. J., Kiehl, J., and Marshall, S.: The Community Earth System Model: A Framework for Collaborative Research, B. Am. Meteorol. Soc., 94, 1339-1360, 2013.

Johnson, C. Y. and Meadows, E. B.: First investigation of ambient positive-ion composition to $219 \mathrm{~km}$ by rocket-borne spectrometer, J. Geophys. Res., 60, 193-203, 1955.

Joiner, J. and Aikin, A. C.: Temporal and spatial variations in upper atmospheric $\mathrm{Mg}^{+}$, J. Geophys. Res, 101, 5239-5250, 1996.

Kalashnikova, O., Horanyi, M., Thomas, G. E., and Toon, O. B.: Meteoric Smoke production in the atmosphere, Geophys. Res. Lett.-Space, 27, 3293- 3296, 2000.

Kyrölä, E., Tamminen, J., Leppelmeier, G. W., Sofieva, V., Hassinen, S., Bertaux, K. L., Hauchecorne, A., Dalaudier, F., Cot, C., Korablev, O., Fanton d'Andon, O., Barrot, G., Mangin, A., Théodore, B., Guirlet, M., Etanchaud, F., Snoeijj, P., Koopman, R., Saavedra, L., Fraisse, R., Fussen, D., and Vanhellemont, F.: GOMOS on Envisat: an overview, Adv. Space Res., 33, 10201028, 2004.

Langowski, M. P., von Savigny, C., Burrows, J. P., Feng, W., Plane, J. M. C., Marsh, D. R., Janches, D., Sinnhuber, M., Aikin, A. C., and Liebing, P.: Global investigation of the $\mathrm{Mg}$ atom and ion layers using SCIAMACHY/Envisat observations between 70 and $150 \mathrm{~km}$ altitude and WACCM-Mg model results, Atmos. Chem. Phys., 15, 273-295, https://doi.org/10.5194/acp-15-2732015, 2015.

Langowski, M. P., von Savigny, C., Burrows, J. P., Rozanov, V. V., Dunker, T., Hoppe, U.-P., Sinnhuber, M., and Aikin, A. C.: Retrieval of sodium number density profiles in the mesosphere and lower thermosphere from SCIAMACHY limb emission measurements, Atmos. Meas. Tech., 9, 295-311, https://doi.org/10.5194/amt-9-295-2016, 2016.

Levison, H. P.: Comet Taxonomy, Compl. Inv. Sol. Sys, Astronom. Soc. Pac. Conf. Proc., 107, 173-191, 1996.

Llewellyn, E. J., Lloyd, N. D., Degenstein, D. A., Gattinger, R. L., Petelina, S. V., Bourassa, A. E., Wiensz, J. T., Ivanov, E. V., McDade, I. C., Solheim, B. H., McConnell, J. C., Haley, C. S., von Savigny, C., Sioris, C. E., McLinden, C. A., Griffioen, E., Kaminski, J., Evans, W. F. J., Puckrin, E., Strong, K., Wehrle, V., Hum, R. H., Kendall, J. W., Matsuhita, J., Murtagh, D. P., Brohede, S., Stegman, J., Witt, G., Barnes, G., Payne, W. F., Piché, L., Smith, K., Warshaw, G., Deslauriers, D.-L., Marchand, P., Richardson, E. H., King, R. A., Wevers, I., McCreath,
W., Kyrölä, E., Oikarinen, L., Leppelmeier, G. W., Auvinen, H., Mégie, G., Hauchecorne, A., Lefèvre, F., de La Nöe, J., Ricaud, P., Frisk, U., Sjoberg, F., von Schéele, F., and Nordh, L.: The OSIRIS instrument on the Odin spacecraft, Can. J. Phys., 82, 411-422, 2004.

Love, S. G. and Brownlee, D. E.: A direct measurement of the terrestrial mass accretion rate of cosmic dust, Science, 262, 550553, 1993.

Marsh, D. R., Garcia, R. R., Kinnison, D. E., Boville, B. A., Sassi, F., Solomon, S. C., and Matthes, K.: Modeling the whole atmosphere response to solar cycle changes in radiative and geomagnetic forcing, J. Geophys. Res., 112, D23306, https://doi.org/10.1029/2006JD008306, 2007.

Marsh, D. R., Janches, D., Feng, W., and Plane, J. M. C.: A global model of meteoric sodium, J. Geophys. Res.-Atmos., 118, 11442-11452, 2013a.

Marsh, D. R., Mills, M. J., Kinnison., D. E., Lamarque, J. F., Calvo, N., and Polvani, L. M.: Climate Change from 1850 to 2005 Simulated in CESM1 (WACCM), J. Climate, 26, 7372-7391, $2013 \mathrm{~b}$.

McNeil, W. J., Lai, S. T., and Murad, E.: Differential ablation of cosmic dust and implications for the relative abundances of atmospheric metals, J. Geophys. Res., 103, 10899-10911, 1998.

Merkel, A. W., Marsh, D. R., Gettelman, A., and Jensen, E. J.: On the relationship of polar mesospheric cloud ice water content, particle radius and mesospheric temperature and its use in multi-dimensional models, Atmos. Chem. Phys., 9, 8889-8901, https://doi.org/10.5194/acp-9-8889-2009, 2009.

Mills, M. J., Schmidt, A., Easter, R., Solomon, S., Kinnison, D. E., Ghan, S. J., Neely, R. R. I., Marsh, D. R., Conley, A., and Bardeen, C. G.: Global volcanic aerosol properties derived from emissions, 1990-2014, using CESM1(WACCM), J. Geophys. Res.-Atmos., 121, 2332-2348, 2016.

Murphy, D. M., Thomson, D. S., and Mahoney, M. J.: In Situ Measurements of Organics, Meteoric Material, Mercury, and Other Elements in Aerosols at 5 to 19 Kilometers, Science, 282, 16641669, 1998.

Nesvorný, D., Jenniskens, P., Levison, H. F., Bottke, W. F., Vokrouhlický, D., and Matthieu, G.: Cometary origin of the Zoodiacal Cloud and carbonaceous micrometeorites. Implications for hot debris disks, Astrophys. J., 713, 816-836, 2010.

Plane, J. M. C.: Atmospheric Chemistry of Meteroric Metals, Chem. Rev., 103, 4963-4984, 2003.

Plane, J. M. C.: Cosmic dust in the earth's atmosphere, J. Atmos. Sol.-Terr. Phys., 41, 6507-6518, 2012.

Plane, J. M. C., Feng, W., Dawkins, E., C. M., Chipperfield, M. P., Höffner, J., Janches, D., and Marsh, D. R.: Resolving the strange behavior of extraterrestrial potassium in the upper atmosphere, Geophys. Res. Lett., 41, 4753-4760, 2014.

Plane, J. M. C., Feng, W., and Dawkins, E. C. M.: The Mesosphere and Metals: Chemistry and Changes, Chem. Rev., 115, 44974541, 2015.

Plane, J. M. C., Gómez Martín, J. C., Feng, W., and Janches, D.: Silicon chemistry in the mesosphere and lower thermosphere, J. Geophys. Res.-Atmos., 121, 3718-3728, 2016.

Rapp, M. and Thomas, G. E.: Modeling the microphysics of mesospheric ice particles: Assessment of current capabilities and basic sensitivities, J. Atmos. Solar-Terr. Phys., 68, 715-744, 2006.

Rienecker, M. M., Suarez, M. J., Gelaro, R., Todling, R., Bacmeister, J., Liu, E., Bosilovich, M. G., Schubert, S. D., Takacs, 
L., Kim, G.-K., Bloom, S., Chen, J., Collins, D., Conaty, A., da Silva, A., Gu, W., Joiner, J., Koster, R. D., Lucchesi, R., Molod, A., Owens, T., Pawson, S., Pegion, P., Redder, C. R., Reichle, R., Robertson, F. R., Ruddick, A. G., Sienkiewicz, M., and Woollen, J.: MERRA: NASA's Modern-Era Retrospective Analysis for Research and Applications, J. Climate, 24, 3624-3648, 2011.

Rodgers, C.: Inverse Methods for Atmospheric Sounding: Theory and Practice, World Scientific, 2000.

Roscoe, H. K. and Hill, J. G. T.: Vertical resolution of oversampled limb-sounding measurements from satellites and aircraft, J. Quant. Spectrosc. Ra., 72, 237-248, 2002.

Rudraswami, N. G., Prasad, M. S., Dey, S., Plane, J. M. C., Feng, W., Carrillo-Sánchez, J. D., and Fernandes, D.: Ablation and Chemical Alteration of Cosmic Dust Particles During Entry into the Earth's Atmosphere, Astrophys. J. Supplem. Ser., 227, 550553, https://doi.org/10.1016/j.jastp.2006.09.006, 2016.

Saunders, R. W. and Plane, J. M. C.: A laboratory study of meteor smoke analogues: Composition, optical properties and growth kinetics, J. Atmos. Sol.-Terr. Phys., 68, 550-553, 2006.

Scharringhausen, M., Aikin, A. C., Burrows, J. P., and Sinnhuber, M.: Global column density retrieval of mesospheric and thermospheric MgI and MgII from SCIAMACHY limb and radiance data, J. Geophys. Res., 113, D13303, https://doi.org/10.1029/2007JD009043, 2008.
Slipher, V. M.: Emissions in the spectrum of the light of the night sky, Publ. Astron. Soc. Pac., 41, 262-263, 1929.

Viehl, T. P., Plane, J. M. C., Feng, W., and Höffner, J.: The photolysis of $\mathrm{FeOH}$ and its effect on the bottomside of the mesospheric Fe layer, Geophys. Res. Lett., 43, 1373-1381, 2016.

Voigt, C., Schlager, H., Luo, B. P., Dörnbrack, A., Roiger, A., Stock, P., Curtius, J., Vössing, H., Borrmann, S., Davies, S., Konopka, P., Schiller, C., Shur, G., and Peter, T.: Nitric Acid Trihydrate (NAT) formation at low NAT supersaturation in Polar Stratospheric Clouds (PSCs), Atmos. Chem. Phys., 5, 13711380, https://doi.org/10.5194/acp-5-1371-2005, 2005.

von Savigny, C., Kaiser, J. W., Bovensmann, H., Burrows, J. P., McDermid, I. S., and Leblanc, T.: Spatial and temporal characterization of SCIAMACHY limb pointing errors during the first three years of the mission, Atmos. Chem. Phys., 5, 2593-2602, https://doi.org/10.5194/acp-5-2593-2005, 2005.

von Savigny, C., Langowski, M. P., Zilker, B., Burrows, J. P., Fussen, D., and Sofieva, V. F.: First mesopause Na retrievals from satellite Na D-line nightglow observations, Geophys. Res. Lett, 43, 12651-12658, 2016.

Vondrak, T., Plane, J. M. C., Broadley, S., and Janches, D.: A chemical model of meteoric ablation, Atmos. Chem. Phys., 8, 70157031, https://doi.org/10.5194/acp-8-7015-2008, 2008. 